\title{
Absorption of aerosols above clouds from POLDER/PARASOL measurements and estimation of their direct radiative effect
}

\author{
F. Peers ${ }^{1}$, F. Waquet ${ }^{1}$, C. Cornet $^{1}$, P. Dubuisson ${ }^{1}$, F. Ducos ${ }^{1}$, P. Goloub ${ }^{1}$, F. Szczap ${ }^{2}$, D. Tanré ${ }^{1}$, and F. Thieuleux ${ }^{1}$ \\ ${ }^{1}$ Laboratoire d'Optique Atmosphérique, Université Lille 1, Villeneuve d'Ascq, France \\ ${ }^{2}$ Laboratoire de Météorologie Physique, Clermont-Ferrand, France
}

Correspondence to: F. Peers (fanny.peers@ed.univ-lille1.fr) and F. Waquet (fabien.waquet@univ-lille1.fr)

Received: 6 August 2014 - Published in Atmos. Chem. Phys. Discuss.: 9 October 2014

Revised: 25 March 2015 - Accepted: 30 March 2015 - Published: 22 April 2015

\begin{abstract}
This study presents an original method to evaluate key parameters for the estimation of the direct radiative effect (DRE) of aerosol above clouds: the absorption of the the cloud albedo. It is based on multi-angle total and polarized radiances both provided by the A-train satellite instrument POLDER - Polarization and Directionality of Earth Reflectances. The sensitivities brought by each kind of measurements are used in a complementary way. Polarization mostly translates scattering processes and is thus used to estimate scattering aerosol optical thickness and aerosol size. On the other hand, total radiances, together with the scattering properties of aerosols, are used to evaluate the absorption optical thickness of aerosols and cloud optical thickness. The retrieval of aerosol and clouds properties (i.e., aerosol and cloud optical thickness, aerosol single scattering albedo and Ångström exponent) is restricted to homogeneous and optically thick clouds (cloud optical thickness larger than 3 ). In addition, a procedure has been developed to process the shortwave DRE of aerosols above clouds. Three case studies have been selected: a case of absorbing biomass burning aerosols above clouds over the southeast Atlantic Ocean, a Siberian biomass burning event and a layer of Saharan dust above clouds off the northwest coast of Africa. Besides these case studies, both algorithms have been applied to the southeast Atlantic Ocean and the results have been averaged during August 2006. The mean DRE is found to be $33.5 \mathrm{~W} \mathrm{~m}^{-2}$ (warming). Finally, the effect of the heterogeneity of clouds has been investigated and reveals that it affects mostly the retrieval of the cloud optical thickness and not greatly the aerosols properties. The homogenous cloud assumption used in both the properties retrieval and the DRE processing leads to a slight underestimation of the DRE.
\end{abstract}

\section{Introduction}

The quantification of the aerosol radiative impact is one of the largest sources of uncertainty in global climate models (Myhre et al., 2013b). These uncertainties are mainly related to aerosols in cloudy conditions through direct, semi-direct and indirect effects. The last two describe the modifications of cloud microphysics due to interactions between clouds and aerosols (Bréon et al., 2002). In particular, the enhancement of the number of cloud condensation nuclei results in a reduction of cloud droplet size, leading in an enhancement of the cloud albedo (Twomey, 1974, 1977), a prolongation of their lifetime and a decrease of precipitation (Albrecht, 1989; Ramanathan et al., 2001). The semi-direct effect refers to changes in cloud formation attributable to the aerosol influences on the vertical stability of the atmosphere (Ackerman et al., 2000; Johnson et al., 2004; Koren et al., 2004; Kaufman et al., 2005). Finally, the direct effect corresponds to the modification of the amount of solar radiation scattered back to space by the clouds due to the presence of an aerosol layer. Figure 1 illustrates the difference in albedo in the top-of-theatmosphere $\Delta \rho$ caused by an aerosol layer versus the albedo of the surface underneath. It has been calculated using the approximate expression given by Lenoble et al. (1982):

$\Delta \rho=\rho-\rho_{\mathrm{s}}=\tau\left(\varpi_{0}(1-g)\left(1-\rho_{\mathrm{s}}\right)^{2}-4\left(1-\varpi_{0}\right) \rho_{\mathrm{s}}\right)$

$\rho_{\mathrm{S}}$ is the surface albedo, and $\rho$, the albedo above the aerosol layer. The aerosol optical thickness $\tau$ is related to the amount of particles and corresponds to the sum of the absorption optical thickness $\tau_{\text {abs }}$ and the scattering one $\tau_{\text {scatt }}$. Single scattering albedo (SSA) $\varpi_{0}$ describes the relative contribution of aerosol scattering to extinction (i.e., scattering and absorption, $\left.\varpi_{0}=\tau_{\text {scatt }} / \tau\right)$. Finally, the aerosol asymmetry factor $g$ 


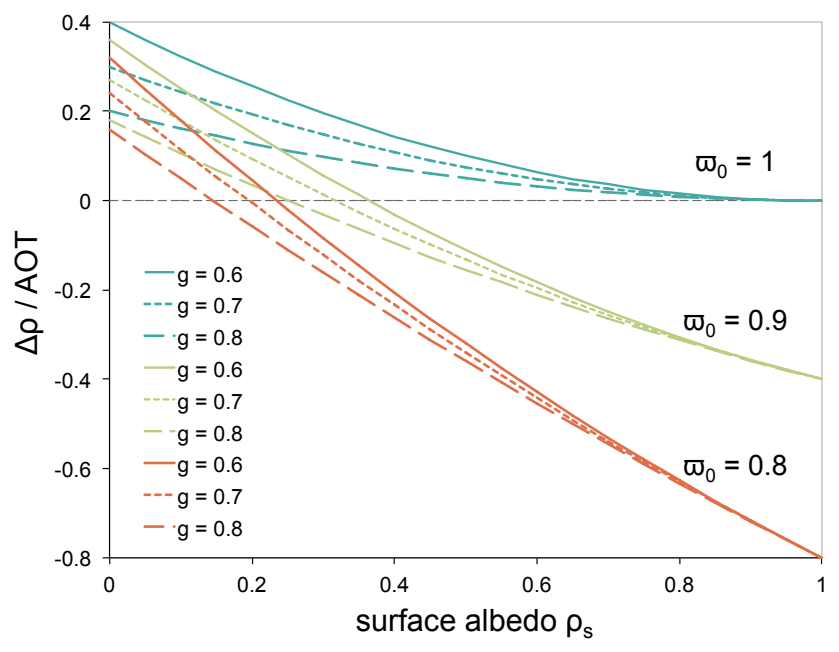

Figure 1. Modification of the albedo at the top of the atmosphere $\Delta \rho$ caused by the presence of an aerosol layer versus the albedo of the surface underneath $\rho_{\mathrm{S}}$ calculated with the approximate expression given by Lenoble et al. (1982). Darker green lines correspond to purely scattering-only aerosols $\left(\varpi_{0}=1\right)$, lighter green to aerosols moderately absorbing $\left(\varpi_{0}=0.9\right)$, orange lines are for absorbing aerosols $\left(\varpi_{0}=0.8\right)$ and $g$ is the asymmetry factor.

characterizes the preferential direction of the scattered light. The difference of albedo and the shortwave direct radiative effect (DRE) of aerosols are directly proportional. A positive difference of albedo means that the surface appears brighter from the top of the atmosphere with aerosols (domination of the scattering process) and thus, it results in a cooling effect $(\mathrm{DRE}<0)$. This is the case for aerosols above a dark surface as, for instance, over ocean. Over bright conditions, such as clouds, the sign of the difference of albedo strongly depends on the absorption of the aerosol layer (i.e., the single scattering albedo): absorbing aerosols can lead to a darkening (warming effect), but for particles which scatter enough, the resulting forcing can be positive (cooling effect). As a consequence, the improvement of the DRE estimation is driven by the accurate knowledge of the albedo of the surface underneath, the amount of aerosols and their level of absorption.

In order to constrain numerical models, satellite aerosol retrievals provide essential information on aerosol and cloud properties, spatial distribution and trends. However, the study of above-cloud aerosol layers is a recent line of research and the radiative effects of aerosols located above clouds remain unconstrained because most current satellite retrievals are limited to cloud-free conditions. In addition, the retrieval of cloud properties that determine the cloud albedo (i.e., the cloud optical thickness and the droplet effective radius) is impacted by the presence of an aerosol layer above (Haywood et al., 2004; Wilcox et al., 2009; Coddington et al., 2010) and consequently, it biases the estimation of the DRE. Active sensors like the Cloud-Aerosol Lidar with Orthogonal Polarization (CALIOP) are dedicated to the analy- sis of the atmospheric vertical profile. An operational algorithm (Winker et al., 2009, 2013; Young and Vaughan, 2009) as well as two alternative research methods (i.e., the depolarization ratio, Hu et al., 2007, and the color-ratio method, Chand et al., 2008) enable the retrieval of the above-cloud aerosol optical thickness (ACAOT). Nevertheless, passive sensors have also shown the ability to extract information from above-cloud aerosol (ACA) measurements and take advantage of their wide spatial coverage. Based on the capacity of aerosols to absorb the UV radiation reflected by the clouds, Torres et al. (2012) have developed a method to calculate the UV aerosol index and, under some assumption on the aerosol properties, to retrieve the ACAOT as well as the aerosol-corrected cloud optical thickness (ACCOT) with the Ozone Monitoring Instrument (OMI). The amount of particles above clouds and the ACCOT can also be retrieved simultaneously using measurements in the visible and shortwave infrared spectrum from the Moderate Resolution Imaging Spectroradiometer (MODIS), thanks to the color-ratio method developed by Jethva et al. (2013).

Contrary to total radiances, polarized measurements are primarily sensitive to the single scattering process and no longer depend on the optical thickness of the cloud when it is thick enough. Waquet et al. (2009, 2013a) have developed a method to retrieve the ACAOT at two wavelengths and therefore the Ångström exponent, using polarized radiances from the Polarization and Directionality of Earth Reflectances (POLDER). Jethva et al. (2014) have carried out a multi-sensor comparison of the above-cloud AOT retrieved from different sensors on board NASA's A-train satellite for a biomass burning event off the southwest coast of Africa. Considering the different kinds of assumptions and measurements used to retrieve the ACAOT, results have shown good consistency over the homogeneous cloud fields. Since aerosol and cloud properties are known, it is possible to process the DRE of aerosols above clouds with a radiative transfer model (Chand et al., 2009; Peters et al., 2011; Costantino and Bréon, 2013; Meyer et al., 2013). However, most of the ACAOT retrievals presented above do not evaluate the aerosol single scattering albedo. In contrast, the DRE of aerosols above clouds can also be evaluated without making assumptions about aerosol microphysics thanks to the algorithm developed by De Graaf et al. (2012) for Scanning Imaging Absorption Spectrometer for Atmospheric Chartography (SCIAMACHY) measurements. Hyperspectral reflectance from polluted cloud conditions is converted into flux and subtracted from clean cloud conditions. The latter is modeled thanks to cloud properties derived from SCIAMACHY measurements in the shortwave infrared spectrum. While this method is expected to work efficiently for finemode aerosols as their interactions at longer wavelengths are minimal or even non-existent, it may not work for coarsemode dust aerosols due to their radiative influence at longer wavelengths. 
All those retrieval methods have shown that both total and polarized radiances are sensitive to ACA. The POLDER instrument on PARASOL satellite has the benefit of measuring both for several viewing angles and wavelengths (Tanré et al., 2011). In the next section of this paper, we will evaluate the contribution brought by the combination of the scattering information provided by polarization and the absorption one given by total radiances. We will explore an improved retrieval method for ACA conditions over ocean, based on the work of Waquet et al. (2013a) for the three main parameters required to estimate the DRE: the ACAOT, the ACCOT and the SSA of ACA. The previous algorithm has already demonstrated its ability to detect different kinds of particles (i.e., biomass burning, pollution and dust) over clouds at a global scale (Waquet et al., 2013b). In the third section, we will present a module for the processing of ACA DRE. Beyond their types, aerosol absorption properties are expected to vary a lot depending on space, time and formation processes (Dubovik et al., 2002) and thus, resulting in different radiative responses. Both algorithms have been applied to three events with contrasted aerosol properties: absorbing biomass burning aerosols off the southwest coast of Africa, and scattering ones from Siberia and Saharan dust. Then, aerosol and cloud properties as well as the DRE have been evaluated and averaged during August 2006 over the southeast Atlantic Ocean. This region is a key area for the study of aerosol impacts in cloudy skies since biomass burning particles from Africa are usually transported westward over clouds during the dry season. The case studies and the monthly results will be shown in Sect. 4. Thereafter, the impact of cloud heterogeneity on our estimation of ACA parameters and the DRE will be examined in Sect. 5. Conclusion will be drawn in Sect. 6.

\section{Retrieval method}

\subsection{Description}

Polarized measurements can be used to extract information from ACA conditions (Waquet et al., 2009, 2013a; Hasekamp, 2010; Knobelspiesse et al., 2011) owing to the specific signal produced by cloud liquid droplets. Figure 2 illustrates polarized radiances processed with the SOS (successive order of scattering) code (Deuzé et al., 1989) for a cloudy atmosphere, with (colored lines) and without aerosols above (black line). It should be noted that, in this paper, the radiance refers to the normalized quantity according to the definition given by Herman et al. (2005). Regarding the clean cloud signal, the amount of polarized light generated by the cloud is very weak at side scattering angles (70-130 $)$. Also, it does not depend on the COT as long as it is larger than 3.0. The aerosol model used for the polluted cloud cases corresponds to fine-mode particles with an effective radius of $0.10 \mu \mathrm{m}$. The scattering AOT is fixed (i.e., AOT $_{\text {scatt }}=0.18$ )

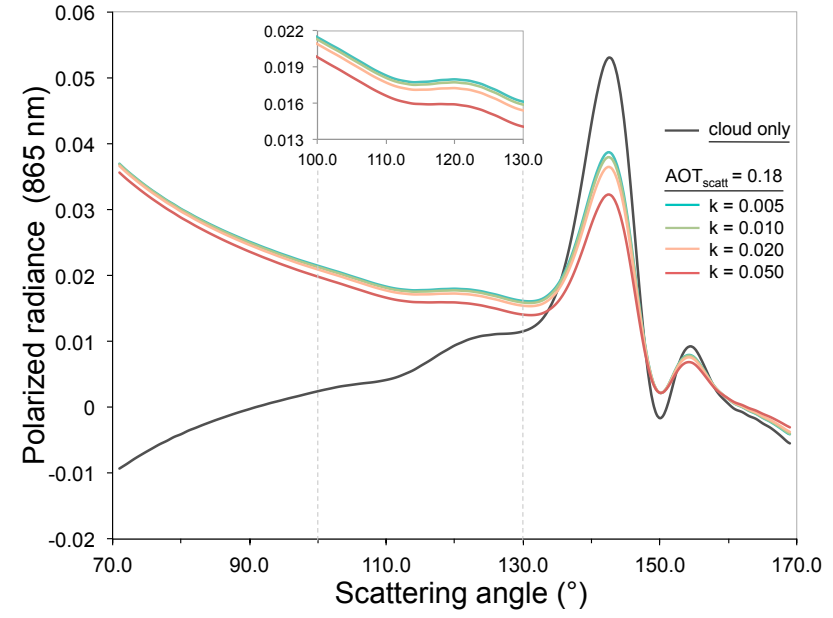

Figure 2. Simulated polarized radiance at $865 \mathrm{~nm}$ plotted against the scattering angle. Black line corresponds to the cloud only $\left(\mathrm{COT}=10, r_{\text {eff }}=10 \mu \mathrm{m}\right)$. Colored lines are for an above-cloud aerosol layer. The effective radius of aerosols is $0.10 \mu \mathrm{m}$. Several absorption AOT values (i.e., various $k$ ) have been considered but the scattering AOT is fixed at 0.18 . The inset focuses on polarized radiances of aerosols above clouds for scattering angles between 100 and $130^{\circ}$. Complementary information about vertical distributions and properties of aerosols and clouds can be found in Table 1 (see polarized look up table (LUT)).

while the level of absorption (i.e., AOT $_{\mathrm{abs}}$ ) has been stretched through the complex part of the refractive index $k$. The scattering of light by fine-mode aerosols causes the creation of an additional polarized signal at side scattering angles. Moreover, in accordance with the sensitivity analysis performed by Waquet et al. (2013a), the effect of absorption processes on polarization is weak for any scattering angles lower than $130^{\circ}$. Thus, the signal is mostly attributable to scattering processes. At the same time, cloud water droplets produce a large peak of polarization at about $140^{\circ}$ that is strongly attenuated by aerosols for ACA events. These two effects can be used to derive aerosol scattering properties from multidirectional polarized measurements like the ones provided by POLDER.

In the case of clean sky condition (i.e., without aerosols), the total radiances scattered by cloud water droplets are relatively spectrally independent from the UV to the shortwave infrared (SWIR) part of the spectrum (De Graaf et al., 2012). At the same time, those wavelengths are sensitive to aerosol effects (i.e., absorption and scattering) whose spectral behaviors depend strongly on the microphysics of the particles (e.g., size, chemical composition, shape). Consequently, the presence of an above-cloud aerosol layer affects the signal that can be measured by satellite instruments: the spectral tendency of aerosol absorption leads to a modification of the apparent color of the clouds. Simulations of the upwelling radiance at 490 and $865 \mathrm{~nm}$ for ACA events have been processed with a radiative transfer code based on the adding- 


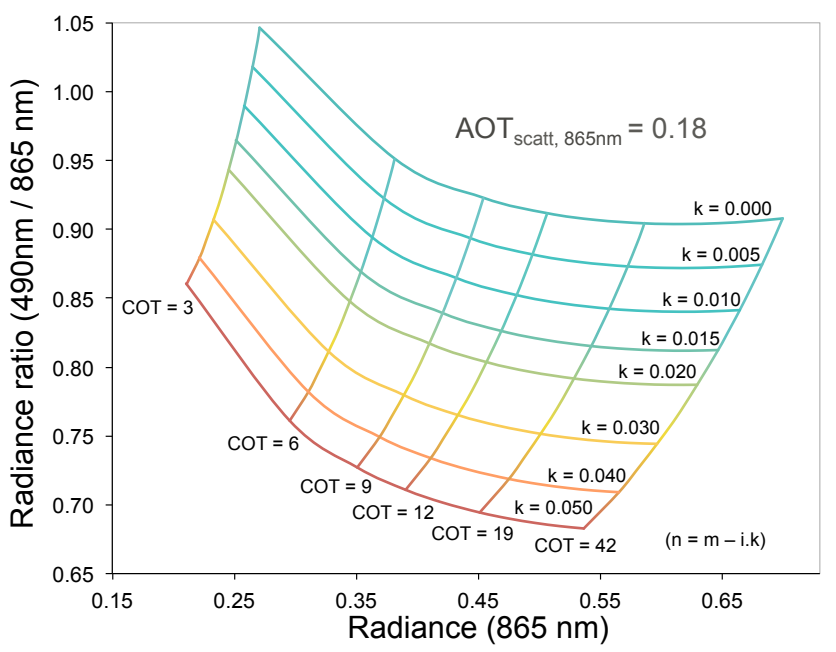

Figure 3. Radiance ratio $L_{490 \mathrm{~nm}} / L_{865 \mathrm{~nm}}$ as a function of the radiance at $865 \mathrm{~nm}$. Signals have been simulated for aerosols with an effective radius of $0.10 \mu \mathrm{m}$, an effective radius of cloud droplet of $10 \mu \mathrm{m}$ (for more information about aerosol and cloud properties and vertical distribution, see Table 1, total radiance LUT column). The scattering AOT is set and several absorption AOT and several COT values are considered. Calculations have been carried out for a solar zenith angle $\theta_{\mathrm{s}}=41.3^{\circ}$, a viewing angle $\theta_{\mathrm{v}}=41.3^{\circ}$ and a relative azimuth $\varphi_{\mathrm{r}}=180^{\circ}$.

doubling method (De Haan et al., 1987). In the same way as Fig. 3 in the study of Jethva et al. (2013), Fig. 3 here highlights the color ratio effect. The radiance ratio $\left(L_{490} / L_{865}\right)$ is plotted against the SWIR radiance $\left(L_{865}\right)$ for several cloud optical thickness (COT) values and for aerosols with an effective radius of $0.1 \mu \mathrm{m}$. Similarly to the previous figure, the scattering AOT is fixed and several absorption AOT values are considered. The complex part of the refractive index $k$ is set equal at both wavelengths. This plot clearly illustrates the enhancement of the spectral contrast with absorption. For a given value of the radiance ratio, the $865 \mathrm{~nm}$ band provides the sensitivity to the COT. That is to say, radiances at 490 and $865 \mathrm{~nm}$ can be interpreted as a coupled ACCOT and absorption ACAOT as long as the scattering optical thickness of aerosol and their size are known.

\subsection{POLDER data}

The POLDER instrument is the main part of the PARASOL's payload (Polarization and Anisotropy of Reflectances for Atmospheric Science coupled with Observations from a Lidar) that have flown from 2004 to 2013, including 5 years as a part of the A-train constellation. It provides radiances for nine spectral bands between 443 and $1020 \mathrm{~nm}$ as well as polarization measurements over 3 (i.e., 490, 670 and $865 \mathrm{~nm})$. Thanks to its two-dimensional charge-coupled device camera, the instrument acquires a series of images, which allow the target to be seen from up to 16 viewing angles. The ground spatial resolution of POLDER at nadir is
$5.3 \times 6.2 \mathrm{~km}$. A new version of Level $1(\mathrm{v} 03.02)$ products was released by the CNES at the end of 2014 including an improvement of the radiometric calibration (Fougnie et al., 2007). However, the data used in this paper corresponds to the previous version (i.e., PARASOL Collection 2 v02.04).

\subsection{Algorithm}

The distinctive feature of the method presented here is to combine the information provided by both total and polarized multidirectional radiances from POLDER. The first step consists of estimating the scattering optical thickness and the aerosol size with polarization. We proceed with the look up table (LUT) approach described by Waquet et al. (2013a). Polarized radiances at 670 and $865 \mathrm{~nm}$ have been computed with the SOS code (Deuzé et al., 1989) for seven models of aerosols that follow a lognormal size distribution (cf. Table 1). Six of them correspond to spherical aerosols from the fine mode with radius from 0.06 to $0.16 \mu \mathrm{m}$ and assuming a complex refractive index of $1.47-0.01 i$. The last one is a nonspherical model for dust with a refractive index of $1.47-0.0007 i$. The retrieval of the scattering AOT is attempted for each $6 \times 6 \mathrm{~km}$ POLDER's pixel when the COT given by MODIS is larger than 3.0. If fine-mode aerosols have been identified, the estimation of the scattering AOT is based on the polarized signal measured for scattering angle lower than $130^{\circ}$. At that point, a first estimation of the extinction AOT is made based on the absorption assumed for the selected aerosol model (i.e., $k_{\text {assumption }}$ ). Results are then subjected to several filters in order to improve their quality: data must be well fitted, clouds have to be homogeneous and both cloud edges and cirrus are rejected according to criteria based on POLDER and MODIS products. Filtered AOT values are then aggregated from $6 \times 6 \mathrm{~km}$ to $18 \times 18 \mathrm{~km}$ and pixels with a standard deviation (SD) of the AOT values larger than 0.1 are excluded in order to prevent cloud edge contamination. Eventually, the scattering AOT is recovered using the SSA of the aerosol model with the same absorption assumption used at first (i.e., $k_{\text {assumption }}$ ):

$\tau_{\mathrm{scatt}, \lambda}=\varpi_{0, \lambda, k_{\text {assumption }}} \tau_{\mathrm{ext}, \lambda, k_{\mathrm{assumption}},}$,

$\tau_{\text {scatt }}$ is the scattering AOT, $\tau_{\text {ext }}$ the extinction AOT retrieved with polarization, $\varpi_{0}$ the SSA corresponding to the model used for the retrieval and $\lambda$ referring to the wavelength. We consider that the aerosol size corresponds to the one of the model with the nearest model (i.e., not interpolated).

The second part of the method aims at evaluating the absorption of ACA and the ACCOT using multidirectional radiances at 490 and $865 \mathrm{~nm}$ and the information on properties already provided by polarization. Once again, the process consists of a comparison with radiance LUT. For computing time reasons, we have chosen to process radiances with the adding-doubling code (De Haan et al., 1987) instead of the one used for the polarized LUT (i.e., SOS code). The models are based on the seven ones previously considered 
grows called the color ratio effect. Since aerosol absorption has a spectral signature, it produces stronger absorption effects at shorter wavelengths than at longer ones.

\subsection{Sensitivity analysis}

The method developed hereinbefore requires assumptions at different stages of the retrieval. The aim of this section is to analyze the resulting impact on the retrieval. To serve this purpose, POLDER's observations have been modeled with the same radiative transfer code used for the LUT, considering several aerosol and cloud models. These modeled signals have been used as inputs for the algorithm. It implies that errors due to the polarization part of the retrieval are investigated and then impacted on the total radiances step.

We first examine the assumption regarding aerosol properties. In order to retrieve the scattering AOT, it is assumed that polarized measurements are weakly sensitive to aerosol absorption. This approximation is expected to become less consistent when the aerosol layer is very absorbing (i.e., large AOT and low SSA values). This leads to an error in the estimation of the scattering AOT that could affect the retrieval of the SSA. The second assumption concerns the real part of the refractive index $m$ fixed at 1.47 for the retrieval. To assess the impact of these assumptions, we have considered three absorbing aerosol models with different refractive indices $\mathrm{n}: 1.42-0.03 i, 1.47-0.03 i$ and $1.52-0.03 i$ corresponding to an SSA at $865 \mathrm{~nm}$ of $0.735,0.772$ and 0.801 , respectively. The real parts of the refractive indices have been chosen to be representative of the variability observed within the aerosol fine mode (Dubovik et al., 2002). Aerosols have an effective radius of $0.1 \mu \mathrm{m}$ and their mean altitude is $3 \mathrm{~km}$. The cloud layer used to model the signal has a top altitude of $0.75 \mathrm{~km}$, an optical thickness of 10 and a droplet effective radius of $10 \mu \mathrm{m}$. Total and polarized radiances have been simulated for absorbing aerosol layers with increasing AOT. Finally, the DRE of aerosols has been processed using the radiative transfer code GAME (Global Atmospheric ModEl) (Dubuisson et al., 2004), based on the properties of the modeled conditions on the one hand, and those retrieved by the algorithm on the other hand. In Fig. 5, the aerosol and cloud parameters retrieved (green lines) and used in the reference states (i.e., input simulations - grey lines) are plotted as a function of the AOT at $865 \mathrm{~nm}$. The middle column (i.e., $n=1.47-0.03 i$ ) shows the biases due to the approximation that polarized radiances translate the scattering process only while the left and the right ones (i.e., $n=1.42-0.03 i$ and $1.52-0.03 i$ ) also present the effect due to the assumption on the real part of the refractive index.

- The first two rows display the total and the scattering AOT. For $m=1.42$ and 1.47 , the algorithm underestimates the AOT. This error comes from the underestimation of the scattering AOT during the polarized part of the retrieval. For AOT values lower than 0.2, we observe a bias around $20 \%$ on the AOT. In the case of extreme events, with AOT values around 0.6 (i.e., 1.5 at $550 \mathrm{~nm}$ ), the AOT is underestimated by $26.7 \%$ for $m=1.47$ and $24.1 \%$ for $m=1.42$. Conversely, the algorithm overestimates the AOT when $m=1.52$. It has to be noted that the retrieved aerosol radius is larger than the one used to model the signal $(0.12 \mu \mathrm{m}$ instead of $0.1 \mu \mathrm{m})$. In that case, the largest error in the AOT (i.e., 25.3\%) is observed at $\mathrm{AOT}=0.2$. Then, the error slowly decreases with the AOT because of the compensation by aerosol absorption, reaching $16.8 \%$ at $\mathrm{AOT}=0.6$.

- The third and fourth rows of Fig. 5 show the absorption AOT and the SSA values versus the total AOT. In spite of the error in the scattering AOT, it is interesting to observe that the biases on the absorption AOT values are small. Because of the sensitivity of total radiances to the absorption of the aerosol layer, the algorithm compensates for the bias of the scattering AOT due to the first part by an error in the SSA. As a consequence, a negative (positive) error in the scattering AOT goes together with an underestimation (overestimation) of the SSA. For AOT $=0.6$, a bias of -0.055 was observed for $m=1.42$ and $m=1.47$, and a bias of +0.033 was observed for $m=1.52$.

- Plots of the fifth row represent the retrieved COT. They reveal that both the approximation regarding polarized radiance and the assumption on the real part of the refractive index have a limited impact on the COT estimation. In this analysis, the largest COT bias is \pm 0.3 .

- Finally, the bottom row focuses on the evolution of the DRE of aerosols with the modeled AOT. The DRE estimated with aerosol and cloud properties retrieved by the algorithm is close to the one processed with the properties of the modeled conditions. This can be explained by the reliable estimation of the aerosol layer absorption: as suggested by Eq. (1), the absorption AOT is the leading parameter in the estimation of the DRE for large values of the albedo of the conditions underneath. The largest bias $\left(+9.7 \mathrm{~W} \mathrm{~m}^{-2}\right)$ has been obtained for $\mathrm{AOT}=0.6$ and $m=1.52$. Otherwise, the bias is always lower than $\pm 6.4 \mathrm{~W} \mathrm{~m}^{-2}$ for AOT values lower than 0.2 and lower than $\pm 1 \mathrm{~W} \mathrm{~m}^{-2}$ for AOT values lower than 0.1 .

Secondly, we look at the assumption on the size distribution of the coarse-mode particles. For the retrieval, we only consider one model for dust. It is defined by a bimodal lognormal size distribution with an Ångström exponent of 0.36 (Waquet et al., 2013a). The signal has been modeled for coarse-mode particles with an Ångström exponent of 0.02 and 0.6 and an $\mathrm{AOT}=0.6$. The method appears to allow for a consistent evaluation of the SSA at $490 \mathrm{~nm}$ (error $<1 \%$ ) in spite of the error in the optical thickness and on the Ångström exponent 

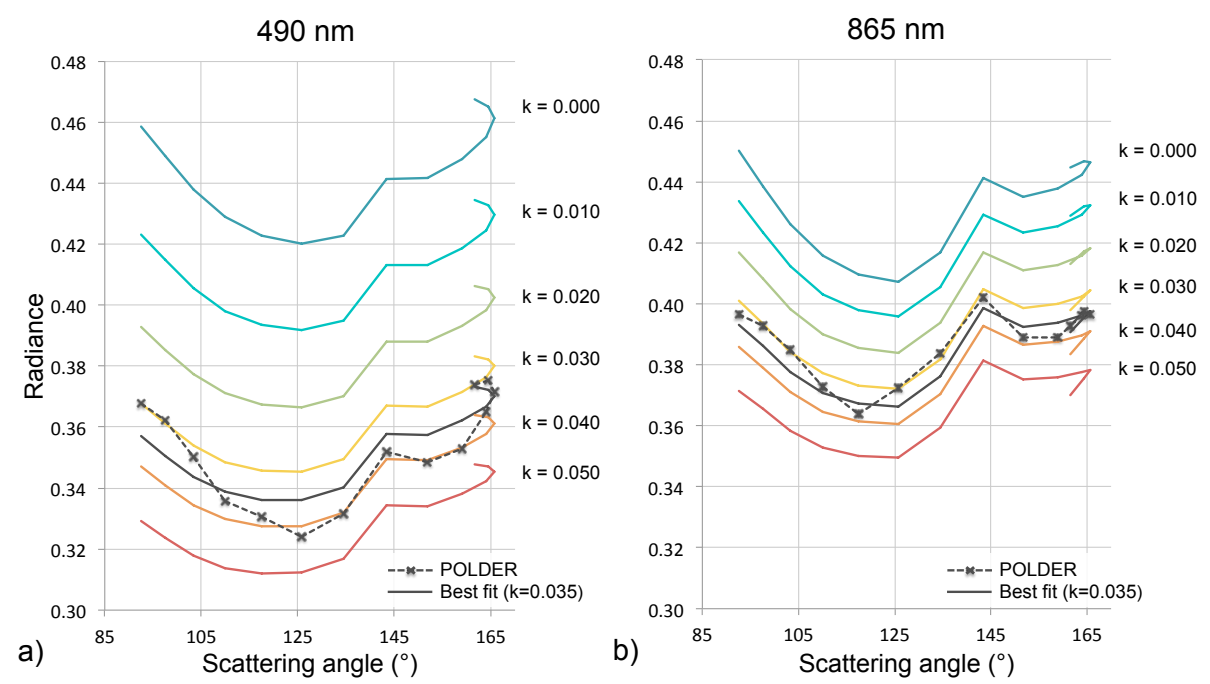

Figure 4. Example of measured and simulated total radiances for one pixel at $490 \mathrm{~nm}$ (a) and $865 \mathrm{~nm}$ (b). The dashed black lines are for the measurements and the continuous black ones are for the simulated signals corresponding to the solution (i.e., COT $=12.4 ; k=0.035$; AOT $=0.14)$. Other colored lines correspond to the signal simulated for the same COT, the same scattering AOT values and for several $k$ (i.e., different absorption AOT values).

(error in AOT around $24 \%$ and in the Ångström exponent of $100 \%)$.

The last assumption about aerosols that has been investigated concerns the vertical distribution of the aerosol layer. We have processed the signal for an aerosol top altitude of 4 and $6 \mathrm{~km}$ and the algorithm has retrieved the correct aerosol and cloud properties. In polarization, the bands used to retrieve the scattering AOT (i.e., 670 and $865 \mathrm{~nm}$ ) are weakly impacted by the molecular contribution. Aerosols in the clouds do not contribute to the creation of a polarized signal at side scattering angles. Hence the polarized radiances are not impacted by the aerosol vertical distribution as long as the aerosol layer is distinct from the cloud.

Regarding the cloud hypothesis, we test the impact of considering only one cloud droplet effective radius $\left(r_{\text {eff,cld }}=10 \mu \mathrm{m}\right)$ for the estimation of the aerosol absorption and the ACCOT by modeling the signal for $r_{\text {eff,cld }}=6$ and $20 \mu \mathrm{m}$ with a COT of 10 . The approximation regarding the effective radius of cloud droplet is the main source of error in the COT estimation. While the error in the COT due to aerosol hypothesis does not exceed $3 \%$, this one may lead to a COT bias of $\pm 10 \%$, which is in agreement with the study of Rossow et al. (1989). However, statistical analysis of the conditions studied hereafter have shown that more than $70 \%$ of the clouds have an effective radius ranging between 8 and $16 \mu \mathrm{m}$. Lastly, we have investigated the influence of the cloud top altitude by considering $z_{\text {top,cld }}=2$ and $4 \mathrm{~km}$. For each case, the algorithm has retrieved the correct parameters for clouds and aerosols.

\section{Radiative effect estimation}

As previously shown, the accurate knowledge of the aerosol and cloud properties is required for estimating the direct radiative forcing due to an above-cloud aerosol layer. At the top of the atmosphere (TOA), this instantaneous DRE $\Delta F\left(\theta_{\mathrm{s}}\right)$ is expressed as a flux difference given by

$$
\begin{aligned}
\Delta F\left(\theta_{\mathrm{S}}\right) & =\left(F^{\downarrow}\left(\theta_{\mathrm{S}}\right)-F_{\text {cloud+aer }}^{\uparrow}\left(\theta_{\mathrm{S}}\right)\right) \\
& -\left(F^{\downarrow}\left(\theta_{\mathrm{S}}\right)-F_{\text {cloud }}^{\uparrow}\left(\theta_{\mathrm{S}}\right)\right) \\
& =F_{\text {cloud }}^{\uparrow}\left(\theta_{\mathrm{S}}\right)-F_{\text {cloud+aer }}^{\uparrow}\left(\theta_{\mathrm{S}}\right) .
\end{aligned}
$$

$\theta_{\mathrm{S}}$ being the solar zenith angle, $F^{\downarrow}$ the downward flux at the TOA, $F_{\text {cloud+aer }}^{\uparrow}$ the upward flux when aerosols are present and $F_{\text {cloud }}^{\uparrow}$ corresponds to the flux reflected by clouds with no aerosol above.

Since the approximate method described earlier (Eq. 1) could lead to results not accurate enough for coarse-mode particles, we have chosen to found our approach on exact calculations based on the radiative transfer code GAME (Dubuisson et al., 2004). Instantaneous shortwave radiative forcing (i.e., from 0.2 to $4 \mu \mathrm{m}$ ) has been precomputed for several solar zenith angles. Regarding fine-mode aerosols, they are assumed to be only composed of black carbon. In other words, the imaginary part of the refractive index is constant in the shortwave (grey aerosols) and corresponds to the one retrieved by our algorithm. For dust aerosols, the spectral dependence of the absorption is based on the work of Balkanski et al. (2007), adjusting the UV imaginary part of the refractive index with the retrieved value at $490 \mathrm{~nm}$. In addition to the aerosol and cloud properties derived using the 

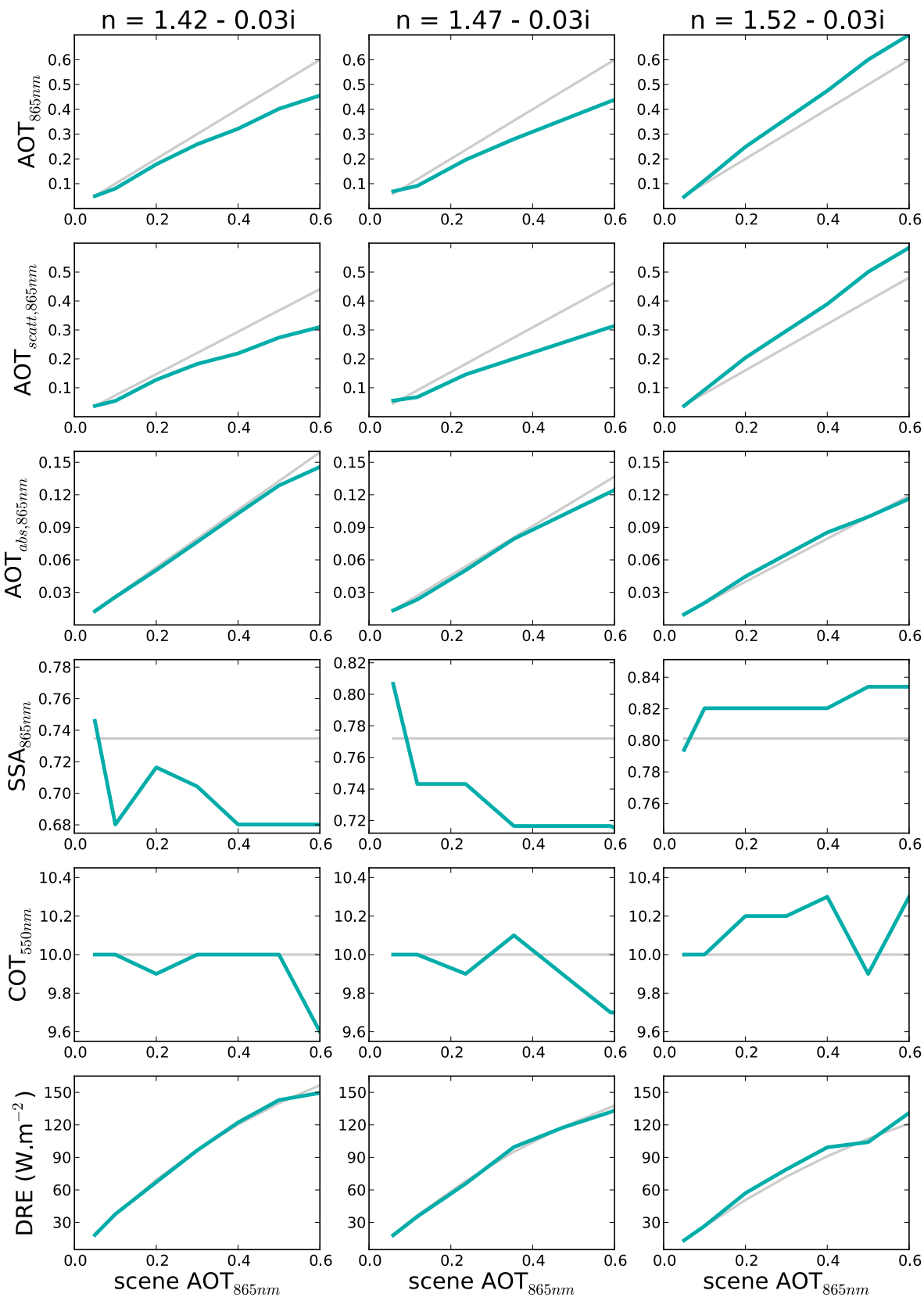

- property of the modeled scene

retrieved property

Figure 5. Sensitivity of the properties of ACA conditions with different aerosol models. From top to the bottom: total AOT, scattering AOT, absorption AOT and SSA at $865 \mathrm{~nm}$, COT at $550 \mathrm{~nm}$ and the shortwave DRE of aerosols. Grey lines correspond to the properties of the actual modeled conditions and green lines to those retrieved by the algorithm. The aerosol model of the first column has a refractive index $n$ equal to $1.42-0.03 i$, the second, $n=1.47-0.03 i$ and the third, $n=1.52-0.03 i$. Aerosols have an effective radius of $0.1 \mu \mathrm{m}$ and the effective radius of the cloud water droplets is $10 \mu \mathrm{m}$.

methods described hereinbefore (i.e., ACCOT, ACAOT, the aerosol size and their absorption), the LUT takes into account several cloud droplet effective radii and atmospheric vertical distributions. Those latest are characterized by the cloud top height (considering an aerosol layer between 1 and $2 \mathrm{~km}$ above the cloud), the amount of absorbing gases (i.e., ozone and water vapor) and the atmospheric model (i.e., the pressure, temperature and gases vertical profiles). The DRE is obtained by interpolation of the LUT.

Regarding the additional input data, the information about the cloud droplets size comes from MODIS (Nakajima and King, 1990). The cloud top height is derived from the 

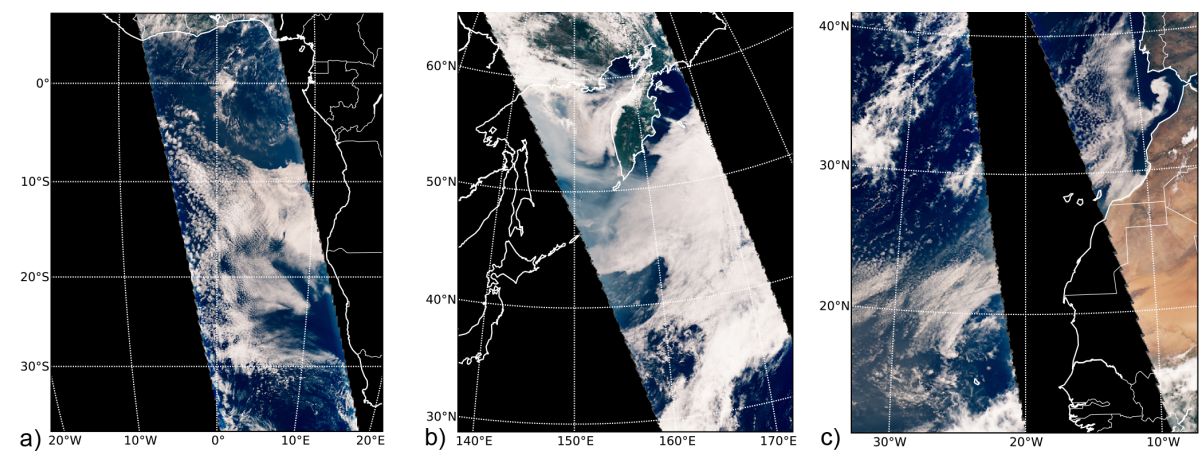

Figure 6. True color POLDER/PARASOL RGB composite (a) over the southeast Atlantic Ocean on 4 August 2008, (b) off the east coast of Russian on 3 July 2008 and (c) over the North Atlantic Ocean on 4 August 2008.

POLDER apparent $\mathrm{O}_{2}$ cloud top pressure (Vanbauce et al., 2003) since the $\mathrm{O}_{2}$ retrieval allows a reliable estimation of the cloud top height in the presence of an aerosol layer above (Waquet et al., 2009). The ozone and water vapor contents are given by meteorological modeling. Finally, the atmospheric vertical profile depends on the seasons and the geographic location (Cole et al., 1965; i.e., mid-latitude, tropical, sub-arctic summer and winter).

\section{Results}

\subsection{Case studies}

The RGB images of the three selected case studies are shown in Fig. 6. The first one (Fig. 6a) is related to a biomass burning event during the dry season in the south of Africa, the second (Fig. 6b) concerns Siberian biomass burning aerosols transported above clouds, and the last one (Fig. 6c) is about Saharan dust. For each case, the retrieved parameters (i.e., the ACAOT, the aerosol scattering albedo, their Ångström exponent and the ACCOT) will be shown as well as the estimation of the DRE.

\subsubsection{African biomass burning aerosols}

From June to October, biomass burning particles from manmade vegetation fires are frequently observed above the persistent deck of stratocumulus covers off the southwest coast of Africa. On 4 August 2008 (Fig. 6a), biomass burning aerosols were observed over clouds. Under the CALIOP track (not shown), the aerosol layer is located between 3 and $5 \mathrm{~km}$ and the cloud top at $1 \mathrm{~km}$.

The evaluation of aerosol and cloud properties has been performed over ocean and results are displayed in Fig. 7. The ACAOT (Fig. 7a) reaches high values up to 0.74 at $865 \mathrm{~nm}$. As expected, aerosols are found to belong to the fine mode with effective radius, from $0.10 \mu \mathrm{m}$ close to the coast, to $0.16 \mu \mathrm{m}$ as the plume shifts to the open sea. The Ångström exponent (Fig. 7b), which depends not only on the aerosol size but also slightly on the refractive index, is around 1.94 . Figure 7c shows the low values obtained for the SSA expressing the strong absorbing capability of these aerosols. The lowest SSA values are about 0.73 at $865 \mathrm{~nm}$ near the coast. These aerosols are associated with a complex part of the refractive index around 0.042 . The average SSA of the scenario is 0.875 and 0.840 at 550 and $865 \mathrm{~nm}$, respectively, which is consistent with previous African savannah biomass burning retrieval from AERONET (Dubovik et al., 2002; Sayer et al., 2014) and remote and in situ measurements from the SAFARI 2000 campaign (Leahy et al., 2007; Johnson et al., 2008).

The retrieved ACCOT and the difference with MODIS observations are shown in Fig. 7d and 7e. The pattern followed by the ACCOT is close to the one given by MODIS. However, the comparison between the two methods reveals systematic biases when absorbing aerosols are above clouds. According to previous studies (Haywood et al., 2004; Wilcox et al., 2009; Coddington et al., 2010; Meyer et al., 2013; Jethva et al., 2013), the estimation of the COT that takes into account the aerosol absorption gives higher values than the MODIS MYD06 cloud product. Because aerosols absorb at the wavelengths traditionally used to retrieve the COT, the cloud appears darker, leading to an underestimation of its optical thickness. The impact of the aerosol absorption on the signal gets bigger as the COT increases. Where the clouds are the thickest and the absorption ACAOT the largest (i.e., a small area around $10^{\circ} \mathrm{S}, 8^{\circ} \mathrm{E}$ ), the bias is around 15 . On average over the whole scenario, ACCOT is larger than the MODIS value by 1.2.

Finally, the DRE was estimated and is reported in Fig. 7f. As expected for highly absorbing aerosols, the warming effect reaches high level with DRE values up to $195.0 \mathrm{~W} \mathrm{~m}^{-2}$. As suggested by the approximation given by Lenoble et al. (1982; Eq. 1), such large values are obtained for an important amount of absorbing aerosols collocated with a very bright cloud (i.e., high COT value). However, $77 \%$ of the pixels have a DRE lower than $60 \mathrm{~W} \mathrm{~m}^{-2}$. In contrast, the radiative impact is found to be very weak, even slightly 

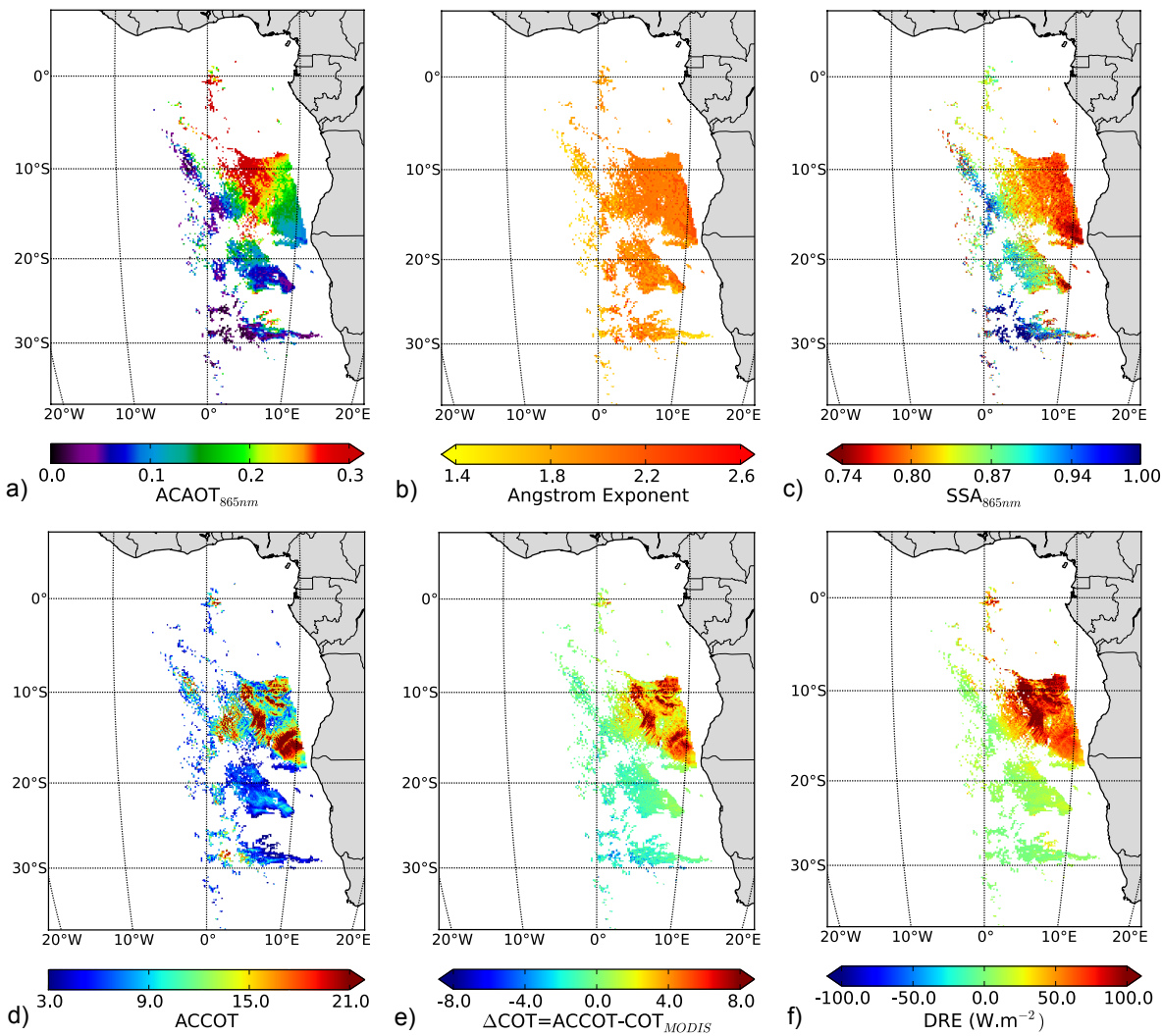

Figure 7. Biomass burning aerosols above clouds off the southwest coast of Africa on 4 August 2008. The panel displays the above-cloud AOT at $865 \mathrm{~nm}$ (a), the Ångström exponent (b), the aerosol SSA at $865 \mathrm{~nm}$ (c), the aerosol-corrected COT at $550 \mathrm{~nm}$ (d), the difference $\triangle$ COT of the ACCOT and the MODIS COT (e) and the DRE of aerosols above clouds in $\mathrm{W} \mathrm{m}^{-2}$ (f).

negative, on the south of the study area, where the clouds are the thinnest and the aerosols less absorbing and in small amount. On average over the region, the instantaneous radiative forcing is evaluated at $36.5 \mathrm{~W} \mathrm{~m}^{-2}$.

\subsubsection{Siberian biomass burning aerosols}

High northern latitudes are also subject to forest fires from June to October. They are mostly of natural origin given favorable climatic conditions (Stocks et al., 2001), and Siberia is one of the most affected areas by boreal fires (Zhang et al., 2003), leading to significant production of smoke. These aerosols can be transported over long distances (Jaffe et al., 2004) and may result in a non-negligible radiative impact (Lee et al., 2005; Péré et al., 2014). Wildfires occurred in the eastern part of Siberia in July 2008 (Paris et al., 2009). On 3 July, aerosols were detected above clouds (Fig. 6b), over the Sea of Okhotsk. Backward trajectories have shown that they came from inland Russia, and the MODIS fire product (Giglio et al., 2003) suggests that they may be attributable to fires that took place on the east coast of Russia. According to CALIOP, the cloud top is at around $1 \mathrm{~km}$ and the aerosol layer is located at about $2 \mathrm{~km}$ in the north of the study area $\left(55^{\circ} \mathrm{N}\right)$ and goes up to $4 \mathrm{~km}$ as we move southward $\left(45^{\circ} \mathrm{N}\right)$.
The results of the algorithm are reported in Fig. 8. Like for the previous case, the conditions reveals an important amount of particles transported above clouds with an average ACAOT (Fig. 8a) of 0.31 and a peak at 3.0 south of the Kamchatka Peninsula $\left(50^{\circ} \mathrm{N}\right)$. On the northwest side of the peninsula, aerosol radii are found to be between 0.10 and $0.12 \mu \mathrm{m}$ and, on the other side, the retrieved radii are a bit larger (between 0.12 and $0.16 \mu \mathrm{m}$ ). In parallel, slightly larger values of the Angström exponent (Fig. 8b) are found in the northern part of the study area (mean value of 2.19) than in the southern part (mean value of 2.02). Despite the fact that aerosols have the same size as for the African event, the Ångström exponent reached higher values for the boreal emission. This is explained by the difference in aerosol absorption properties. The evaluated SSA (shown in Fig. 8c) appears to be closer to 1.0 with a mean value of 0.959 against 0.840 for the previous case study. It points out the scattering nature of the boreal biomass burning aerosols compared to those of the African savannah, in accordance with the study of Dubovik et al. (2002). Moreover, one can also note the variability of the aerosol absorption of this event: the northern part is associated not only to smallest particles, but also to more absorbing particles with a SSA value of 0.943 (i.e., a mean complex refractive index of 0.008 ) compared to 0.964 

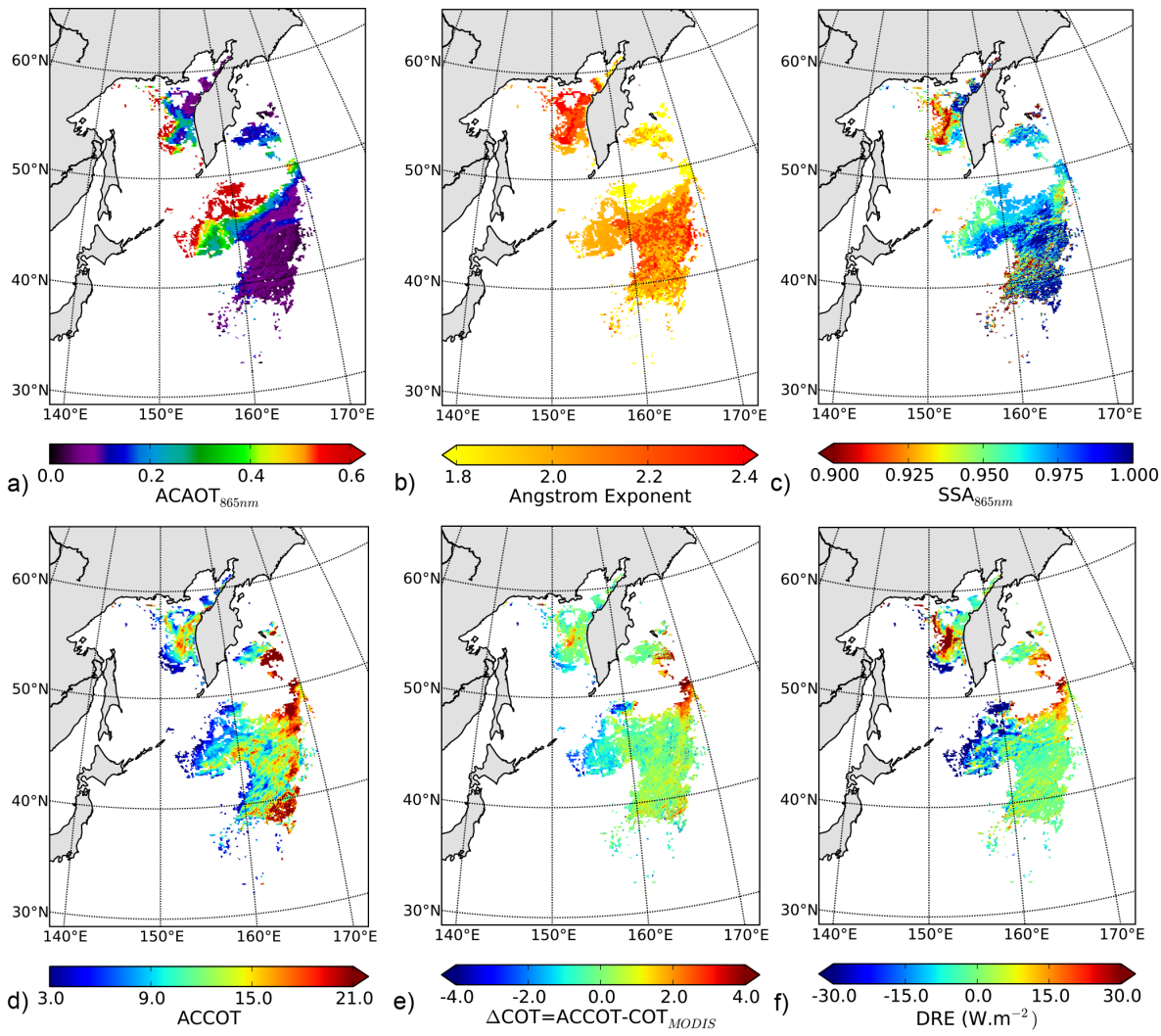

Figure 8. Same as Fig. 7 for biomass burning aerosols from Siberia on 3 July 2008.

(respectively 0.005) in the south. This difference may come from aerosol aging: back trajectories suggest that air masses left inland Russia 3 days before arriving in the southern area while it took only 1 day to arrive in the northern part of the plume.

Like for the African biomass burning event, the ACCOT (Fig. 8d) is found to be in good spatial agreement with the MODIS product. Additionally, given the weak absorbing character of the overlying aerosol layer, the biases between the two methods (Fig. 8e) are minimal. The thickest clouds are associated with the largest MODIS underestimation (biases up to +12.0 ). Moreover, one can also note the MODIS overestimation of the COT for thin clouds (biases up to -10.7 ).

The evaluation of the DRE obtained for this event is presented in Fig. 8f. Large DRE values are observed in the northern part of the study area with values around $45 \mathrm{~W} \mathrm{~m}^{-2}$ between 54 and $57^{\circ} \mathrm{N}$. Conversely, the southwestern part (longitudes west of $160^{\circ} \mathrm{E}$ ) is associated with large negative DRE of about $-50 \mathrm{~W} \mathrm{~m}^{-2}$. As shown in Eq. (1), the sign of the perturbation depends on the balance between the upscattering and the absorption of the aerosol layer. A warming effect is expected where aerosols are absorbing and the clouds are bright enough. Conversely, if the cloud is not optically thick (i.e., COT $<10$ ) and the aerosols are scattering
(SSA close to 1), the particle layer enhances the albedo, leading to local cooling. However, these large warming and cooling effects are spatially limited and $88 \%$ of the study area have a DRE ranging from -30 to $+30 \mathrm{~W} \mathrm{~m}^{-2}$. On average, the radiative impact is almost neutral with a mean DRE of about $-3.5 \mathrm{~W} \mathrm{~m}^{-2}$.

\subsubsection{Saharan dust}

The last case study is related to Saharan dust lifting, transported westward over the Atlantic Ocean. This kind of scenario is usually associated with high AOT values. The event of 4 August 2008 off the coast of Morocco and Mauritania is not unique. In Fig. 9, we report results for the two POLDER orbits (Fig. 6c). The western part, which is located in the core of a dust plume, has an average ACAOT (Fig. 9a) of 0.59 at $865 \mathrm{~nm}$. The CALIOP profile gives a cloud top altitude around $2 \mathrm{~km}$ and a dust layer at about $4 \mathrm{~km}$. Dust detected off the west coast of Morocco corresponds to a less intense event with a mean ACAOT of 0.27 . It has to be remembered that we only retrieve the absorption of dust in the visible spectrum $(490 \mathrm{~nm})$. Therefore we consider one model of aerosol absorption at $865 \mathrm{~nm}$ (i.e., complex part of the refractive index fixed at 0.007), which corresponds to an SSA of 0.984 for this wavelength. Thus, the Ångström exponent calculated (Fig. 9b) is constant over the study area and is 

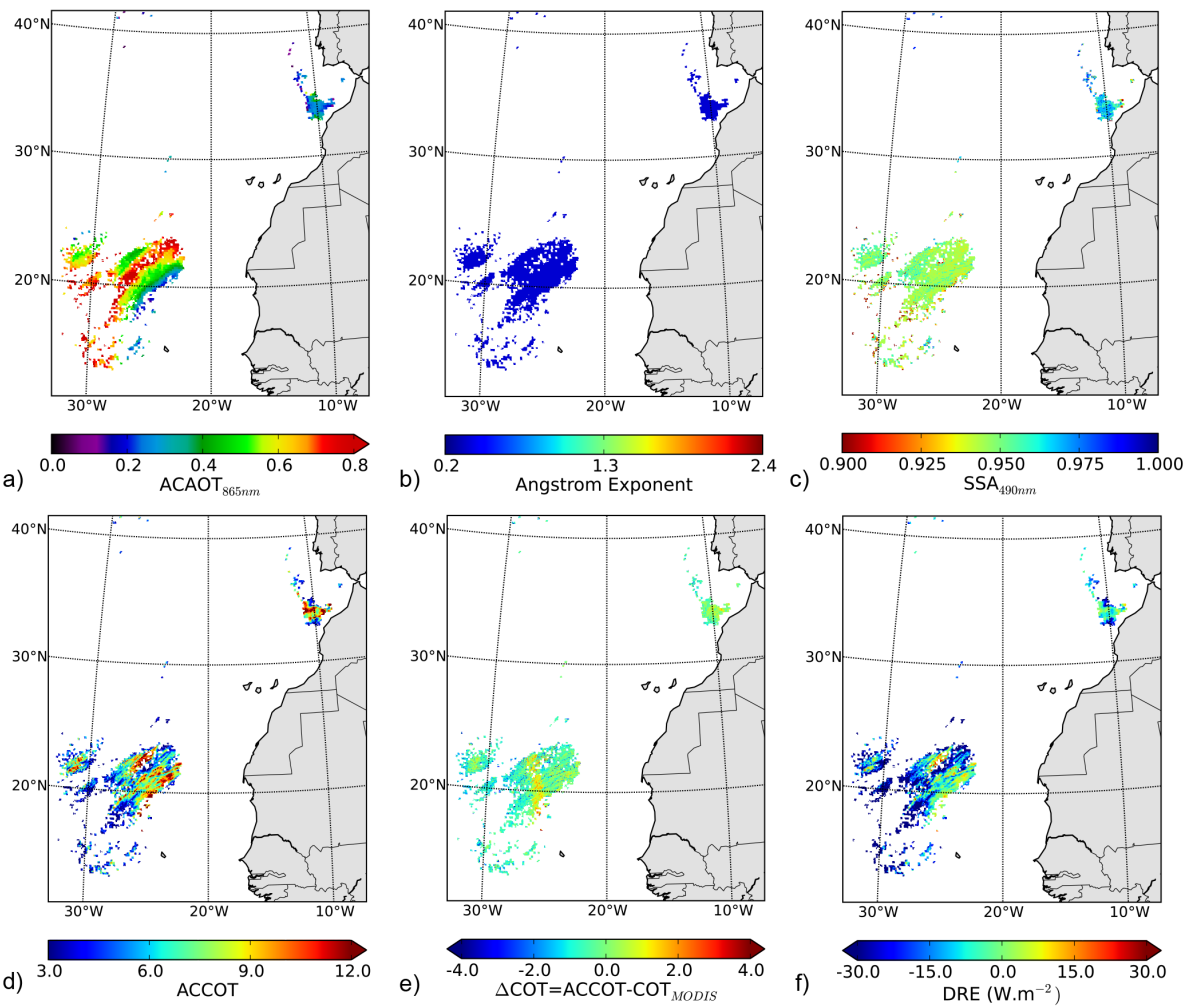

Figure 9. Same as Fig. 7 for Saharan dust above clouds on 4 August 2008, except Fig. 9c that displays the aerosol SSA at $490 \mathrm{~nm}$.

equal to 0.36. Regarding absorption (Fig. 9c), the two events are again quite distinct. On the one hand, the northern area is associated with SSA at $490 \mathrm{~nm}$ around 0.965 with a complex part of the refractive index of 0.001. On the other hand, the western part is slightly more absorbing with a mean SSA of 0.947 and a complex part of the refractive index around 0.002 . These values are consistent with those reported by Dubovik et al. (2002).

Here again, the MODIS evaluation of the COT and our estimation (Fig. 9d) are close. Moreover, the fact that dust does not strongly absorb at $865 \mathrm{~nm}$ (i.e., the wavelength used for the MODIS retrieval of the COT) explains the small discrepancies observed between the two methods (Fig. 9e) (Haywood et al., 2004). However, MODIS overestimates the COT for more than $60 \%$ of the study area with biases up to -5.3 . As for the previous case, this is attributable to the conjunction of thin clouds and scattering aerosols. On average, the bias is equal to -0.2 .

Finally, the DRE of the study area was processed (Fig. 9f). In contrast with the previous cases, the presence of an abovecloud aerosol layer results mostly in a cooling effect, with a negative DRE over $92 \%$ of the study area and an average value of $-18.5 \mathrm{~W} \mathrm{~m}^{-2}$. The maximum and minimum values of the radiative impact (respectively 41.3 and $-91.9 \mathrm{~W} \mathrm{~m}^{-2}$ ) are reached in the western area. One can also notice the correlation between retrieved ACCOT and the DRE. Since the aerosol properties do not show a lot of variability there, it clearly illustrates the influence of the cloud albedo on the calculation of the radiative impact. Thus, the correct estimation of the COT has to be considered in order to accurately evaluate the radiative impact of ACA.

\subsection{Monthly DRE results over the southeast Atlantic Ocean}

The southeast Atlantic Ocean is a preferred area to study aerosol interactions with clouds and radiation because of the aerosol transport above clouds during the August-September dry season. The impact of these biomass burning particles in cloudy conditions are expected to be important not only locally, but also at a wider scale through global teleconnections (Jones et al., 2009; Jones and Haywood, 2012). However, the radiative impact of aerosols for the southwest coast of Africa remains uncertain for global aerosol models, starting with their direct effect (Myhre et al., 2013a).

The aerosol and cloud properties have been evaluated over the southeast Atlantic Ocean during the fire season in $\mathrm{Au}-$ gust 2006. Important events of biomass burning aerosols over clouds were detected, especially between 10 and $24 \mathrm{Au}-$ gust. The largest events (i.e., with an ACAOT larger than 0.2 ) represent $28.9 \%$ of the observations. They are characterized by strongly absorbing aerosols with an SSA of 0.867 at $865 \mathrm{~nm}$. Then, the instantaneous radiative forcing of aerosols above clouds has been computed. The monthly averaged 

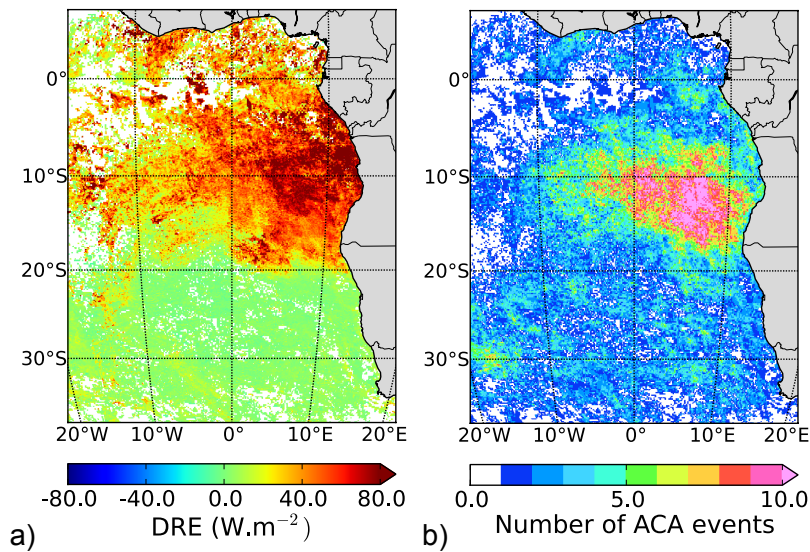

Figure 10. DRE of aerosols above clouds averaged during August 2006 (a) and number of associated events (b). The DRE has been processed over area with a cloud fraction (CF) equal to 1 and $\mathrm{COT} \geq 3$.

DRE values and the corresponding number of observations are reported in Fig. 10a and b, respectively. Each pixel corresponds to three POLDER observations in the mean, with a maximum at 13 observed events off the Angolan coast. As for the case study in August 2008 (Fig. 7), almost all ACA events lead to a warming effect. The maximum values are observed near the coast close to $8^{\circ} \mathrm{S}$ latitude with averaged DRE around $125 \mathrm{~W} \mathrm{~m}^{-2}$, which is consistent with the study of De Graaf et al. (2012).

Figure 11 displays the distribution of the DRE values reached during the month. First, it can be noticed that about $14 \%$ of the events have a DRE between 0.0 and $2.5 \mathrm{~W} \mathrm{~m}^{-2}$. It is important to remember that our method is highly sensitive to the scattering process thanks to polarization measurements. Thus, we are able to detect well conditions with low AOT values or with weak absorption. Combined with thick clouds, these events lead to slightly positive DRE values. In contrast, large warming effects have been observed, with DRE values greater than $75 \mathrm{~W} \mathrm{~m}^{-2}$ over $12.7 \%$ of the observations. Less than $0.2 \%$ of the pixels are even associated with DRE values larger than $220 \mathrm{~W} \mathrm{~m}^{-2}$. These dramatic values have been obtained for high loadings of absorbing aerosols (i.e., AOT values larger than 0.3 and SSA values lower than 0.85 at $865 \mathrm{~nm}$ ) located between 9 and $17 \mathrm{Au}$ gust. However, the estimation of the DRE for those intense events has to be considered with caution since our estimation of the aerosol properties may be less accurate. During the first part of the retrieval, we consider that the aerosol absorption does not impact the polarized signal (Fig. 2). This assumption becomes questionable when the amount of aerosols above clouds is very large. On the other hand, around $5 \%$ of the events have a negative DRE with a minimum at $-41.6 \mathrm{~W} \mathrm{~m}^{-2}$. The average DRE for August 2006 is $33.5 \mathrm{~W} \mathrm{~m}^{-2}$, which is of the same order of magnitude as the value obtained by De Graaf et al. (2012) with SCIAMACHY

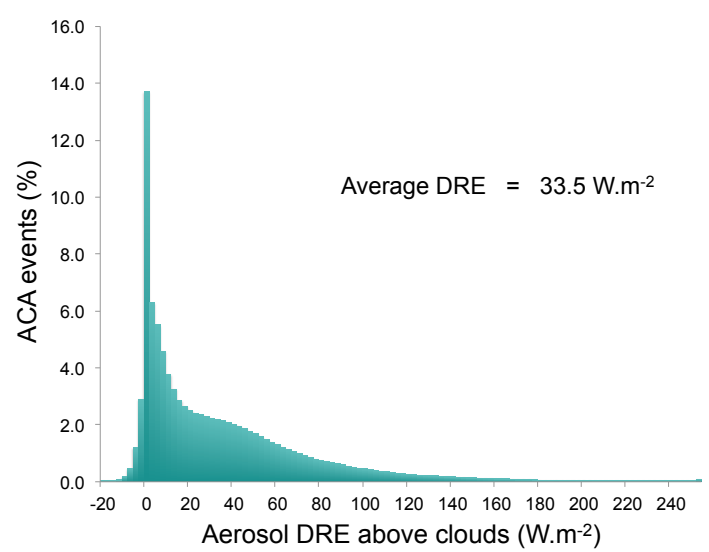

Figure 11. Frequency distribution of the aerosol DRE above clouds for August 2006 for the southeast Atlantic Ocean. Only events with $\mathrm{COT} \geq 3$ and $\mathrm{CF}=1$ are considered.

measurements (i.e., $23 \mathrm{~W} \mathrm{~m}^{-2}$ ). However, it has to be noted that the two satellite instruments do not observe the area at the same time. Changes in conditions between the two measurements (Min and Zhang, 2014) and the difference of solar zenith angles can explain the remaining discrepancies. Furthermore, our algorithm is limited to optically thick cloud $(\mathrm{COT}>3)$ and cannot be applied to fractional cloud coverage.

\section{Cloud heterogeneity effects}

Our method assumes that clouds are horizontally and vertically homogeneous owing to the use of plane-parallel radiative transfer algorithm (i.e., 1-D code). However, numerous studies have shown that the horizontal heterogeneity of clouds affects the scattered radiation measurements through three-dimensional radiative transfer effects (e.g., Marshak and Davis, 2005; Cornet et al., 2013; Zhang et al., 2012). The cloud heterogeneity may thus affect our estimation of aerosol and cloud properties as well as the DRE. To process the signal considering a more realistic cloud field, a 3-D radiative transfer code was used.

\subsection{3-D modeling}

In order to evaluate the impacts of cloud heterogeneities, the signal (i.e., radiances, polarized radiances and fluxes) for one pixel of an ACA event has been modeled with the Monte Carlo radiative transfer code 3DMCPOL (three-dimensional polarized Monte Carlo atmospheric radiative transfer model; Cornet et al., 2010). The cloud field has been generated using the algorithm 3DCLOUD (Szczap et al., 2014) and the heterogeneity controlled through the inhomogeneity parameter $\rho=\sigma(\mathrm{COT}) / \mathrm{COT}$, where $\sigma(\mathrm{COT})$ is the standard deviation of the COT within the pixel. It has to be noted that our algorithm includes a filter for cloud heterogeneity that 


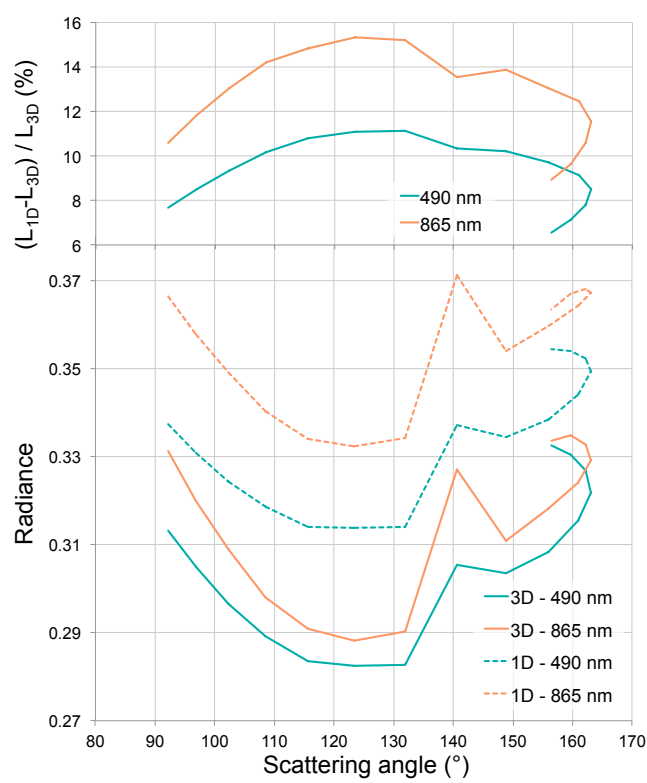

Figure 12. Simulated radiances for aerosols above a heterogeneous cloud $(\sigma(\mathrm{COT}) / \mathrm{COT}=0.6)$ at $490 \mathrm{~nm}$ (green lines) and $865 \mathrm{~nm}$ (orange lines) for a solar zenith angle of $40^{\circ} .3-\mathrm{D}$ signals (continuous lines) have been obtained from the 3DMCPOL code and are based on a cloud field modeled with 3DCLOUD.

rejects pixels with $\sigma(\mathrm{COT})$ larger than 7.0. To process the cloud field, the inhomogeneity parameter $\rho$ has been fixed at 0.6, which represents a standard value for stratocumulus clouds (Szczap et al., 2000a, b). A statistical analysis of the inhomogeneity parameter has been performed over the ACA events sampled by the algorithm. It shows that $\rho=0.6$ can be considered has a high value in this study. The mean COT has been set to 10.0 and the cloud droplet size distribution is assumed to follow a lognormal distribution with $r_{\text {eff }}=11.0 \mu \mathrm{m}$ and $v_{\text {eff }}=0.02$. The overlying aerosol layer is composed of fine-mode particles with an effective radius of $0.12 \mu \mathrm{m}$, an ACAOT of 0.142 at $865 \mathrm{~nm}$ and an SSA of 0.781 (i.e., $k=0.035$ ). The radiative transfer (RT) simulations have been made for a solar incidence angle of $40^{\circ}$ at the three wavelengths used for the retrievals and for a usual POLDER angular configuration.

\subsection{Effects on aerosol and cloud retrieved properties}

The estimation of cloud and aerosol properties using our algorithm was obtained from the 3-D modeled signal. As the horizontal heterogeneity of the cloud field only weakly influences the polarized signal, which is mostly sensitive to the first orders of scattering, the value of the scattering AOT and the aerosol model retrieved during the first part of the method are not affected.

On the contrary, the total radiances are strongly impacted by the cloud heterogeneity. The total radiances modeled with 3DMCPOL are shown in Fig. 12 in addition to those modeled with the 1-D configuration with the mean cloud properties of the 3-D fields. On average, the plane-parallel cloud (i.e., 1-D) produces $9.2 \%$ at $490 \mathrm{~nm}$ and $12.6 \%$ at $865 \mathrm{~nm}$ more signal than the heterogeneous cloud field. To a lesser extent, the angular behavior is also affected by a more pronounced curve from the 3-D modeled signal than from the 1-D one. The overestimation due to the 1-D assumption influences both wavelengths and consequently the radiance ratio $L_{490} / L_{865}$ is less modified than the total signal. It is $94.1 \%$ for the homogeneous cloud and $97.0 \%$ for the heterogeneous one. The aerosol SSA, which is principally sensitive to the radiance ratio, is thus not too impacted by the 3-D effects contrary to the retrieved value of the ACCOT. Using a 1-D assumption, the aerosol absorption is slightly underestimated with an SSA of $0.794(k=0.0325)$ instead of 0.781 at $865 \mathrm{~nm}$. Therefore, the retrieved AOT is also a little smaller than the expected one (i.e., 0.140 instead of 0.142 at $865 \mathrm{~nm}$ ). In parallel, our method evaluates the COT at 7.6, which corresponds to an underestimation of $24 \%$ compared to the mean value (i.e., 10.0).

\subsection{Effect on the DRE}

In the same way that 3-D effects influence radiances, fluxes are expected to vary with the heterogeneity of clouds. The quantification of the aerosol DRE for realistic heterogeneous cloud conditions would need 3-D radiative transfer modeling of the fluxes, which is too time consuming. To evaluate the error in the DRE due to the homogeneous cloud assumption, we compare the differences between, on the one hand, the 3-D TOA fluxes with and without aerosols for the case described in the previous section and, on the other hand, 1-D TOA fluxes with the 1-D equivalent aerosol and cloud properties (i.e., $\mathrm{COT}=7.6$; AOT $_{865 \mathrm{~nm}}=0.140 ; k=0.0325$ ). For computing time reasons, the analysis focuses on fluxes processed at $490 \mathrm{~nm}$. The results obtained from both modelings are shown in Table 2. The fluxes computed with the 1-D assumption, which corresponds to the one obtained with our method, is close to the ones given by the 3-D modeling (underestimation lower than $2.5 \%$ ). We also note that the difference between 3-D and 1-D modeling is smaller for the polluted cloud scenario than for the clean cloud, which means that the aerosols tend to smooth the under-cloud heterogeneity. The exact $\mathrm{DRE}_{0.490 \mu \mathrm{m}}$ (i.e., computed with the 3-D modeling) is equal to $92.06 \mathrm{~W} \mathrm{~m}^{-2} \mu \mathrm{m}^{-1}$, while we obtained $81.92 \mathrm{~W} \mathrm{~m}^{-2} \mu^{-1}$ with the 1-D assumption. Therefore, considering a plane-parallel cloud for both retrieval and DRE processing leads to a slight underestimation of the radiative impact of aerosols, in the case of cloud heterogeneity. For the events presented in this paper (i.e., which meet our selection criteria), the obtained values can be seen as a lower bound for the ACA DRE. Finally, let us mention that this error is expected to be smaller at higher wavelengths and consequently for the solar DRE since the effect of aerosol absorption is the largest in the UV. 
Table 2. Fluxes for polluted and clean conditions and DRE $\left(\mathrm{W} \mathrm{m}^{-2} \mu \mathrm{m}^{-1}\right)$ at the TOA at $0.490 \mu \mathrm{m}$ modeled using 3-D and 1-D assumptions.

\begin{tabular}{lrrr}
\hline & 3-D modeling & 1-D modeling & $\left(F_{1-\mathrm{D}}-F_{3-\mathrm{D}}\right) / F_{3-\mathrm{D}}(\%)$ \\
\hline$F_{\text {cloud+aer }}^{\uparrow}$ & 569.01 & 564.48 & -0.79 \\
$F_{\text {cloud }}^{\uparrow}$ & 661.07 & 646.40 & -2.22 \\
$\mathrm{DRE}=F_{\text {cloud }}^{\uparrow} F_{\text {cloud+aer }}^{\uparrow}$ & 92.06 & 81.92 & -11.01 \\
\hline
\end{tabular}

\section{Conclusion}

In this study, we introduced a new approach for the retrieval of aerosol and cloud properties (i.e., AOT, SSA and COT) when an aerosol layer lies above a liquid cloud over the ocean. Its range of application is restricted to homogeneous clouds with COT values larger than 3 . The strong point of the algorithm is to combine the sensitivity provided by both total and polarized measurements from the passive satellite instrument POLDER. In the first step, the information on the scattering state of the aerosol layer is given by polarized radiances. The presence of an aerosol layer above a thick liquid cloud leads to a significant enhancement of the polarization at the side scattering angle that is used to retrieve the scattering AOT and the aerosol size. Then, these properties together with total radiances are used to determine simultaneously the absorption of the aerosol layer and the COT. In that way, this method allows the retrieving of the aerosol layer properties with minimal assumptions and the cloud properties corrected from the aerosol absorption.

Nevertheless, the impact of the approximations and the assumptions of the method have been assessed. The largest uncertainty about the SSA is due to the approximation about the weak sensitivity of polarized radiances to absorption. When the aerosol size distribution is dominated by the fine mode, an underestimation of -0.055 can be expected for an extreme event of absorbing aerosols above clouds (i.e., $\mathrm{AOT}_{865 \mathrm{~nm}}=0.6$ and $\mathrm{SSA}_{865 \mathrm{~nm}}=0.77$ ). Otherwise, the bias of the SSA is below 0.03. It has to be pointed out that the underestimation of the SSA always goes together with an underestimation of the scattering AOT. As a consequence, the algorithm presented here provides a reliable estimation of the absorption AOT, which is among the most important parameters for evaluating the DRE of aerosols above clouds.

The algorithm has shown its ability to retrieved aerosol and cloud properties for three case studies with very different characteristics. The first one is related to a biomass burning event off the southwest coast of Africa, which is an area frequently used for ACA studies. As expected, these aerosols are found to be strongly absorbing with an SSA value of 0.84 at $865 \mathrm{~nm}$. Moreover, the COT given by MODIS is largely underestimated over the study area, which highlights the importance of taking into account the absorption of aerosol for the COT retrieval. The second example is devoted to Siberian biomass burning. It illustrates the high variability of ACA properties with an average particle SSA of 0.96. In contrast with the previous event, the enhancement of scattering due to these aerosols may cause an overestimation of the COT by MODIS. Finally, the algorithm can be used not only on fine-mode aerosols above clouds, but also on dust particles. The study of Saharan dust transported over clouds has revealed the ability of the method to evaluate the differential dust absorption of visible light at a short wavelength for a given value at $865 \mathrm{~nm}$. It should be added that low differences have been observed between our COT retrieval and the MODIS one where AOT is the smallest. Such biases have already been observed by Zeng et al. (2012) and are primarily due to the differences of instrument characteristics.

Furthermore, we developed a procedure to evaluate the DRE of aerosols above clouds based on exact calculations. The radiative impact processed for the three case studies confirms the need of accurately quantifying the aerosol absorption and the brightness of underneath the cloud. Thick clouds in association with highly absorbing aerosols translate into a warming effect and can reach high DRE values as for the African biomass burning aerosols. Conversely, a cooling effect can be observed under low aerosol absorption and thin cloud conditions as for the Saharan dust event. The estimated DRE for Siberian biomass burning aerosols is spatially contrasted since both cloud and aerosol properties show variability.

The algorithm has been applied to 1 month of measurements over the southeast Atlantic Ocean. August 2006 is characterized by an important amount of absorbing biomass burning aerosols above the permanent stratocumulus deck. The DRE has been processed. The presence of the aerosol layer above bright clouds is responsible for a large radiative impact. The monthly averaged value over the study area is estimated at $33.5 \mathrm{~W} \mathrm{~m}^{-2}$, which is of the same order of magnitude as the estimation of De Graaf et al. (2012; i.e., $23 \mathrm{~W} \mathrm{~m}^{-2}$ ). Let us point out that differences between the results of this study and the literature are expected and are mainly due to the selection of the ACA events: this analysis does not include thin clouds (i.e., COT $<3$ ) and fractional cloud coverage conditions which leads to biased high the DRE. The algorithm developed here could provide aerosol and cloud properties that can be used to better constrain numerical models, leading to a reduction of their uncertainty.

Some efforts still have to be made to enhance our knowledge of aerosols above clouds. Currently, the described 
method allows the retrieval of aerosol and cloud properties only over the ocean. The procedure has to be extended to ACA events over land, which requires paying attention to the contribution of the surface to the measurements. Another key point is the study of aerosols over thin layers of clouds. The first part of the algorithm relies on the independence of the polarized signal for optically thick clouds. To advance further, scenarii with aerosols in fractional cloud coverage have to be investigated. The cloud inhomogeneity also affects the radiances and fluxes of ACA areas. Thus, we have examined the impact of considering a plane-parallel cloud on the aerosol and cloud properties as well as the DRE. On the one hand, the retrieval of aerosol properties is weakly biased since polarized radiances and radiance ratio are not significantly affected by cloud heterogeneity. Finally, the homogeneous cloud assumption leads to an underestimation of the DRE of aerosols. This bias remains small in this study because cases with too heterogeneous clouds are rejected. However, a thorough analysis of the effect of the homogeneous cloud assumption on the estimation of the DRE would provide a significant contribution to the scientific field.

The first results obtained for ACA over the ocean are promising and confirm the need for both global and temporal distribution aerosol and cloud properties. Thus, our next target will be to analyze POLDER measurements over the whole database and to give a first estimation of the global DRE of aerosols over cloudy skies.

Acknowledgements. This work was supported by the Programme National de Télédétection Spatiale (PNTS, http://www.insu.cnrs.fr/ pnts), grant nos. PNTS-2013-10 and PNTS-2014-02. The authors are grateful to CNES, NASA and the ICARE data and services center.

The authors acknowledge the support of France Grilles for providing the computing resources of the French National Grid Infrastructure.

The authors would like to thank the reviewers for their valuable comments and suggestions that considerably improved the article. Finally, they are grateful to the editor, Paola Formenti, for her help during the editorial process.

Edited by: P. Formenti

\section{References}

Ackerman, A. S., Toon, O. B., Stevens, D. E., Heymsfield, A. J., Ramanathan, V., and Welton, E. J.: Reduction of tropical cloudiness by soot, Science, 288, 1042-1047, 2000.

Albrecht, B. A.: Aerosols, cloud microphysics, and fractional cloudiness, Science, 245, 1227-1230, 1989.

Balkanski, Y., Schulz, M., Claquin, T., and Guibert, S.: Reevaluation of Mineral aerosol radiative forcings suggests a better agreement with satellite and AERONET data, Atmos. Chem. Phys., 7, 81-95, doi:10.5194/acp-7-81-2007, 2007.
Bréon, F. M., Tanré, D., and Generoso, S.: Aerosol effect on cloud droplet size monitored from satellite, Science, 295, 834-838, 2002.

Chand, D., Anderson, T. L., Wood, R., Charlson, R. J., Hu, Y., Liu, Z., and Vaughan, M.: Quantifying above-cloud aerosol using spaceborne lidar for improved understanding of cloudy-sky direct climate forcing, J. Geophys. Res.-Atmos., 113, D13206, doi:10.1029/2007JD009433, 2008.

Chand, D., Wood, R., Anderson, T. L., Satheesh, S. K., and Charlson, R. J.: Satellite-derived direct radiative effect of aerosols dependent on cloud cover, Nat. Geosci., 2, 181-184, 2009.

Coddington, O. M., Pilewskie, P., Redemann, J., Platnick, S., Russell, P. B., Schmidt, K. S., and Vukicevic, T.: Examining the impact of overlying aerosols on the retrieval of cloud optical properties from passive remote sensing, J. Geophys. Res.-Atmos., 115, D10211, doi:10.1029/2009JD012829, 2010.

Cole, A. E., Court, A., and Kantor, A. J.: Model atmospheres, in: Handbook of geophysics and space environment, Chap. 2, edited by: Valley, S. L., McGraw-Hill, New York, 1965.

Cornet, C., Labonnote, L. C., and Szczap, F.: Three-dimensional polarized Monte Carlo atmospheric radiative transfer model (3DMCPOL): 3D effects on polarized visible reflectances of a cirrus cloud, J. Quant. Spectrosc. Ra., 111, 174-186, 2010.

Cornet, C., Szczap, F., Labonnote, L. C., Fauchez, T., Parol, F., Thieuleux, F., Riedi, J., Dubuisson, P., and Ferlay, N.: Evaluation of cloud heterogeneity effects on total and polarized visible radiances as measured by POLDER/PARASOL and consequences for retrieved cloud properties, in: Radiation processes in the atmosphere and ocean (IRS2012): Proceedings of the International Radiation Symposium (IRC/IAMAS), Vol. 1531, No. 1, 99-102, AIP Publishing, 2013.

Costantino, L. and Bréon, F.-M.: Satellite-based estimate of aerosol direct radiative effect over the South-East Atlantic, Atmos. Chem. Phys. Discuss., 13, 23295-23324, doi:10.5194/acpd-1323295-2013, 2013.

Cox, C. and Munk, W.: Measurement of the roughness of the sea surface from photographs of the sun's glitter, JOSA, 44, 838850, 1954.

De Graaf, M., Tilstra, L. G., Wang, P., and Stammes, P.: Retrieval of the aerosol direct radiative effect over clouds from spaceborne spectrometry, J. Geophys. Res.-Atmos., 117, D07207, doi:10.1029/2011JD017160, 2012.

De Haan, J. F., Bosma, P. B., and Hovenier, J. W.: The adding method for multiple scattering calculations of polarized light, Astron. Astrophys., 183, 371-391, 1987.

Deuzé, J. L., Herman, M., and Santer, R.: Fourier series expansion of the transfer equation in the atmosphere-ocean system, J. Quant. Spectrosc. Ra., 41, 483-494, 1989.

Dubovik, O., Holben, B., Eck, T. F., Smirnov, A., Kaufman, Y. J., King, M. D., Tanré, D., and Slutsker, I.: Variability of absorption and optical properties of key aerosol types observed in worldwide locations, J. Atmos. Sci., 59, 590-608, doi:10.1175/15200469(2002)059<0590:VOAAOP>2.0.CO;2, 2002.

Dubuisson, P., Roger, J.-C., Mallet, M., and Dubovik, O.: a code to compute the direct solar radiative forcing: application to anthropogenic aerosols during the Escompte experiment, Proceedings of IRS 2004: Current Problems in Atmospheric Radiation, 2328 August 2004, Busan, Korea, 2004. 
Fougnie, B., Bracco, G., Lafrance, B., Ruffel, C., Hagolle, O., and Tinel, C.: PARASOL in-flight calibration and performance, Appl. Optics, 46, 5435-5451, 2007.

Giglio, L., Descloitres, J., Justice, C. O., Kaufman, Y. J.: An enhanced contextual fire detection algorithm for MODIS, Remote Sens. Environ., 87, 273-282, 2003.

Hasekamp, O. P.: Capability of multi-viewing-angle photopolarimetric measurements for the simultaneous retrieval of aerosol and cloud properties, Atmos. Meas. Tech., 3, 839-851, doi:10.5194/amt-3-839-2010, 2010.

Haywood, J. M., Osborne, S. R., and Abel, S. J.: The effect of overlying absorbing aerosol layers on remote sensing retrievals of cloud effective radius and cloud optical depth, Q. J. Roy. Meteorol. Soc., 130, 779-800, 2004.

Herman, M., Deuzé, J. L., Marchand, A., Roger, B., and Lallart, P.: Aerosol remote sensing from POLDER/ADEOS over the ocean: Improved retrieval using a nonspherical particle model, J. Geophys. Res.-Atmos., 110, D10S02, doi:10.1029/2004JD004798, 2005.

Hu, Y., Vaughan, M., Liu, Z., Powell, K., and Rodier, S.: Retrieving optical depths and lidar ratios for transparent layers above opaque water clouds from CALIPSO lidar measurements, IEEE Geosci. Remote Sens., 4, 523-526, 2007.

Jaffe, D., Bertschi, I., Jaeglé, L., Novelli, P., Reid, J. S., Tanimoto, H., Vingarzan, R., and Westphal, D. L.: Long-range transport of Siberian biomass burning emissions and impact on surface ozone in western North America, Geophys. Res. Lett., 31, L16106, doi:10.1029/2004GL020093, 2004.

Jethva, H., Torres, O., Remer, L. A., and Bhartia, P. K.: A color ratio method for simultaneous retrieval of aerosol and cloud optical thickness of above-cloud absorbing aerosols from passive sensors: Application to MODIS measurements, IEEE T. Geosci. Remote Sens., 51, 3862-3870, 2013.

Jethva, H., Torres, O., Waquet, F., Chand, D., and Hu, Y.: How do A-train sensors intercompare in the retrieval of above-cloud aerosol optical depth? A case study-based assessment, Geophys. Res. Lett., 41, 186-192, doi:10.1002/2013GL058405, 2014.

Johnson, B. T., Shine, K. P., and Forster, P. M.: The semi-direct aerosol effect: Impact of absorbing aerosols on marine stratocumulus, Q. J. Roy. Meteorol. Soc., 130, 1407-1422, 2004.

Johnson, B. T., Osborne, S. R., Haywood, J. M., and Harrison, M. A. J.: Aircraft measurements of biomass burning aerosol over West Africa during DABEX, J. Geophys. Res.-Atmos., 113, D00C06, doi:10.1029/2007JD009451, 2008.

Jones, A. and Haywood, J. M.: Sea-spray geoengineering in the HadGEM2-ES earth-system model: radiative impact and climate response, Atmos. Chem. Phys., 12, 10887-10898, doi:10.5194/acp-12-10887-2012, 2012.

Jones, A., Haywood, J., and Boucher, O.: Climate impacts of geoengineering marine stratocumulus clouds, J. Geophys. Res.Atmos., 114, D10106, doi:10.1029/2008JD011450, 2009.

Kaufman, Y. J., Koren, I., Remer, L. A., Rosenfeld, D., and Rudich, Y.: The effect of smoke, dust, and pollution aerosol on shallow cloud development over the Atlantic Ocean, P. Natl. Acad. Sci. USA, 102, 11207-11212, 2005.

Knobelspiesse, K., Cairns, B., Redemann, J., Bergstrom, R. W., and Stohl, A.: Simultaneous retrieval of aerosol and cloud properties during the MILAGRO field campaign, Atmos. Chem. Phys., 11, 6245-6263, doi:10.5194/acp-11-6245-2011, 2011.
Koren, I., Kaufman, Y. J., Remer, L. A., and Martins, J. V.: Measurement of the effect of Amazon smoke on inhibition of cloud formation, Science, 303, 1342-1345, 2004.

Leahy, L. V., Anderson, T. L., Eck, T. F., and Bergstrom, R. W.: A synthesis of single scattering albedo of biomass burning aerosol over southern Africa during SAFARI 2000, Geophys. Res. Lett., 34, L12814, doi:10.1029/2007GL029697, 2007.

Lee, K. H., Kim, J. E., Kim, Y. J., Kim, J., and von HoyningenHuene, W.: Impact of the smoke aerosol from Russian forest fires on the atmospheric environment over Korea during May 2003, Atmos. Environ., 39, 85-99, 2005.

Lenoble, J., Tanré, D., Deschamps, P. Y., and Herman, M.: A simple method to compute the change in earth-atmosphere radiative balance due to a stratospheric aerosol layer, J. Atmos. Sci., 39, 2565-2576, 1982.

Marshak, A. and Davis, A. (Eds.): 3D Radiative Transfer in Cloudy Atmospheres, Vol. 5117, Springer, Berlin, Heidelberg, 2005.

Meyer, K., Platnick, S., Oreopoulos, L., and Lee, D.: Estimating the direct radiative effect of absorbing aerosols overlying marine boundary layer clouds in the southeast Atlantic using MODIS and CALIOP, J. Geophys. Res.-Atmos., 118, 4801-4815, 2013.

Min, M. and Zhang, Z.: On the influence of cloud fraction diurnal cycle and sub-grid cloud optical thickness variability on all-sky direct aerosol radiative forcing, J. Quant. Spectrosc. Ra., 142, 25-36, 2014.

Myhre, G., Samset, B. H., Schulz, M., Balkanski, Y., Bauer, S., Berntsen, T. K., Bian, H., Bellouin, N., Chin, M., Diehl, T., Easter, R. C., Feichter, J., Ghan, S. J., Hauglustaine, D., Iversen, T., Kinne, S., Kirkevåg, A., Lamarque, J.-F., Lin, G., Liu, X., Lund, M. T., Luo, G., Ma, X., van Noije, T., Penner, J. E., Rasch, P. J., Ruiz, A., Seland, Ø., Skeie, R. B., Stier, P., Takemura, T., Tsigaridis, K., Wang, P., Wang, Z., Xu, L., Yu, H., Yu, F., Yoon, J.-H., Zhang, K., Zhang, H., and Zhou, C.: Radiative forcing of the direct aerosol effect from AeroCom Phase II simulations, Atmos. Chem. Phys., 13, 1853-1877, doi:10.5194/acp-13-18532013, 2013a.

Myhre, G., Shindell, D., Bréon, F.-M., Collins, W., Fuglestvedt, J., Huang, J., Koch, D., Lamarque, J.-F., Lee, D., Mendoza, B., Nakajima, T., Robock, A., Stephens, G., Takemura, T., and Zhang, H.: Anthropogenic and Natural Radiative Forcing, in: Climate Change 2013: The Physical Science Basis. Contribution of Working Group I to the Fifth Assessment Report of the Intergovernmental Panel on Climate Change, edited by: Stocker, T. F., Qin, D., Plattner, G.-K., Tignor, M., Allen, S. K., Boschung, J., Nauels, A., Xia, Y., Bex, V., and Midgley, P. M., Cambridge University Press, Cambridge, UK and New York, NY, USA, 571657, 2013b.

Nakajima, T. and King, M. D.: Determination of the optical thickness and effective particle radius of clouds from reflected solar radiation measurements. Part I: Theory, J. Atmos. Sci., 47, 1878 1893, 1990.

Paris, J.-D., Stohl, A., Nédélec, P., Arshinov, M. Yu., Panchenko, M. V., Shmargunov, V. P., Law, K. S., Belan, B. D., and Ciais, P.: Wildfire smoke in the Siberian Arctic in summer: source characterization and plume evolution from airborne measurements, Atmos. Chem. Phys., 9, 9315-9327, doi:10.5194/acp-9-9315-2009, 2009.

Péré, J. C., Bessagnet, B., Mallet, M., Waquet, F., Chiapello, I., Minvielle, F., Pont, V., and Menut, L.: Direct radiative effect of 
the Russian wildfires and its impact on air temperature and atmospheric dynamics during August 2010, Atmos. Chem. Phys., 14, 1999-2013, doi:10.5194/acp-14-1999-2014, 2014.

Peters, K., Quaas, J., and Bellouin, N.: Effects of absorbing aerosols in cloudy skies: a satellite study over the Atlantic Ocean, Atmos. Chem. Phys., 11, 1393-1404, doi:10.5194/acp-11-13932011, 2011.

Ramanathan, V., Crutzen, P. J., Kiehl J. T., and Rosenfeld, D.: Aerosols, climate, and the hydrological cycle, Science, 294, 2119-2124, 2001.

Rossow, W. B., Garder, L. C., and Lacis, A. A.: Global, seasonal cloud variations from satellite radiance measurements. Part I: Sensitivity of analysis, J. Climate, 2, 419-458, 1989.

Sayer, A. M., Hsu, N. C., Eck, T. F., Smirnov, A., and Holben, B. N.: AERONET-based models of smoke-dominated aerosol near source regions and transported over oceans, and implications for satellite retrievals of aerosol optical depth, Atmos. Chem. Phys., 14, 11493-11523, doi:10.5194/acp-14-11493-2014, 2014.

Stocks, B. J., Wotton, B. M., Flannigan, M. D., Fosberg, M. A., Cahoon, D. R., and Goldammer, J. G.: Boreal forest fire regimes and climate change, Remote Sensing and Climate Modeling: Synergies and Limitations, 233-246, Springer Netherlands, 2001.

Szczap, F., Isaka, H., Saute, M., Guillemet, B., and Gour, Y.: Inhomogeneity effects of 1D and 2D bounded cascade model clouds on their effective radiative properties, Phys. Chem. Earth Pt B, 25, 83-89, 2000a.

Szczap, F., Isaka, H., Saute, M., Guillemet, B., and Ioltukhovski, A.: Effective radiative properties of bounded cascade nonabsorbing clouds: Definition of the equivalent homogeneous cloud approximation, J. Geophys. Res.-Atmos., 105, 20617-20633, $2000 \mathrm{~b}$.

Szczap, F., Gour, Y., Fauchez, T., Cornet, C., Faure, T., Jourdan, O., Penide, G., and Dubuisson, P.: A flexible three-dimensional stratocumulus, cumulus and cirrus cloud generator (3DCLOUD) based on drastically simplified atmospheric equations and the Fourier transform framework, Geosci. Model Dev., 7, 17791801, doi:10.5194/gmd-7-1779-2014, 2014.

Tanré, D., Bréon, F. M., Deuzé, J. L., Dubovik, O., Ducos, F., François, P., Goloub, P., Herman, M., Lifermann, A., and Waquet, F.: Remote sensing of aerosols by using polarized, directional and spectral measurements within the A-Train: the PARASOL mission, Atmos. Meas. Tech., 4, 1383-1395, doi:10.5194/amt-4-1383-2011, 2011.

Torres, O., Jethva, H., and Bhartia, P. K.: Retrieval of Aerosol Optical Depth above Clouds from OMI Observations: Sensitivity Analysis and Case Studies, J. Atmos. Sci., 69, 1037-1053, doi:10.1175/JAS-D-11-0130.1, 2012.

Twomey, S.: Pollution and the planetary albedo, Atmos. Environ., 8, 1251-1256, 1974.

Twomey, S.: The influence of pollution on the shortwave albedo of clouds, J. Atmos. Sci., 34, 1149-1152, 1977.
Vanbauce, C., Cadet, B., and Marchand, R. T.: Comparison of POLDER apparent and corrected oxygen pressure to ARM/MMCR cloud boundary pressures, Geophys. Res. Lett., 30, 1212, doi:10.1029/2002GL016449, 2003.

Waquet, F., Riedi, J., Labonnote, L. C., Goloub, P., Cairns, B., Deuzé, J. L., and Tanré, D.: Aerosol Remote Sensing over Clouds Using A-Train Observations, J. Atmos. Sci., 66, 2468-2480, doi:10.1175/2009JAS3026.1, 2009.

Waquet, F., Cornet, C., Deuzé, J.-L., Dubovik, O., Ducos, F., Goloub, P., Herman, M., Lapyonok, T., Labonnote, L. C., Riedi, J., Tanré, D., Thieuleux, F., and Vanbauce, C.: Retrieval of aerosol microphysical and optical properties above liquid clouds from POLDER/PARASOL polarization measurements, Atmos. Meas. Tech., 6, 991-1016, doi:10.5194/amt-6-991-2013, $2013 \mathrm{a}$.

Waquet, F., Peers, F., Ducos, F., Goloub, P., Platnick, S., Riedi, J., Tanré, D., and Thieuleux, F.: Global analysis of aerosol properties above clouds, Geophys. Res. Lett., 40, 5809-5814, $2013 \mathrm{~b}$.

Wilcox, E. M. and Platnick, S.: Estimate of the impact of absorbing aerosol over cloud on the MODIS retrievals of cloud optical thickness and effective radius using two independent retrievals of liquid water path, J. Geophys. Res.-Atmos., 114, D05210, doi:10.1029/2008JD010589, 2009.

Winker, D. M., Vaughan, M. A., Omar, A., Hu, Y., Powell, K. A., Liu, Z., Hunt., W., and Young, S. A.: Overview of the CALIPSO mission and CALIOP data processing algorithms, J. Atmos. Ocean. Technol., 26, 2310-2323, doi:10.1175/2009JTECHA1281.1, 2009.

Winker, D. M., Tackett, J. L., Getzewich, B. J., Liu, Z., Vaughan, M. A., and Rogers, R. R.: The global 3-D distribution of tropospheric aerosols as characterized by CALIOP, Atmos. Chem Phys., 13, 3345-3361, doi:10.5194/acp-13-3345-2013, 2013.

Young, S. A. and Vaughan, M. A.: The retrieval of profiles of particulate extinction from Cloud-Aerosol Lidar Infrared Pathfinder Satellite Observations (CALIPSO) data: Algorithm description, J. Atmos. Ocean. Technol., 26, 1105-1119, doi:10.1175/2008JTECHA1221.1, 2009.

Zeng, S., Cornet, C., Parol, F., Riedi, J., and Thieuleux, F.: A better understanding of cloud optical thickness derived from the passive sensors MODIS/AQUA and POLDER/PARASOL in the A-Train constellation, Atmos. Chem. Phys., 12, 11245-11259, doi:10.5194/acp-12-11245-2012, 2012.

Zhang, Y. H., Wooster, M. J., Tutubalina, O., and Perry, G. L. W.: Monthly burned area and forest fire carbon emission estimates for the Russian Federation from SPOT VGT, Remote Sens. Environ., 87, 1-15, 2003.

Zhang, Z., Ackerman, A. S., Feingold, G., Platnick, S., Pincus, R., and Xue, H.: Effects of cloud horizontal inhomogeneity and drizzle on remote sensing of cloud droplet effective radius: Case studies based on large-eddy simulations, J. Geophys. Res.Atmos., 117, D19208, doi:10.1029/2012JD017655, 2012. 